\title{
A sensitivity study on the retrieval of aerosol vertical profiles using the oxygen A-band
}

\author{
Santo Fedele Colosimo ${ }^{1}$, Vijay Natraj ${ }^{2}$, Stanley P. Sander ${ }^{2}$, and Jochen Stutz ${ }^{1}$ \\ ${ }^{1}$ Department of Atmospheric and Oceanic Sciences, UCLA, Los Angeles, CA, USA \\ ${ }^{2}$ Jet Propulsion Laboratory, Caltech, Pasadena, CA, USA \\ Correspondence to: S. F. Colosimo (fedele@atmos.ucla.edu)
}

Received: 1 September 2015 - Published in Atmos. Meas. Tech. Discuss.: 16 November 2015

Revised: 13 April 2016 - Accepted: 14 April 2016 - Published: 29 April 2016

\begin{abstract}
Atmospheric absorption in the $\mathrm{O}_{2}$ A-band (12 950-13 $200 \mathrm{~cm}^{-1}$ ) offers a unique opportunity to retrieve aerosol extinction profiles from space-borne measurements due to the large dynamic range of optical thickness in that spectral region. Absorptions in strong $\mathrm{O}_{2}$ lines are saturated; therefore, any radiance measured in these lines originates from scattering in the upper part of the atmosphere. Outside of $\mathrm{O}_{2}$ lines, or in weak lines, the atmospheric column absorption is small, and light penetrates to lower atmospheric layers, allowing for the quantification of aerosols and other scatterers near the surface.

While the principle of aerosol profile retrieval using $\mathrm{O}_{2}$ A-band absorption from space is well-known, a thorough quantification of the information content, i.e., the amount of vertical profile information that can be obtained, and the dependence of the information content on the spectral resolution of the measurements, has not been thoroughly conducted. Here, we use the linearized vector radiative transfer model VLIDORT to perform spectrally resolved simulations of atmospheric radiation in the $\mathrm{O}_{2}$ A-band for four different aerosol extinction profile scenarios: urban (urban-rural areas), highly polluted (megacity areas with large aerosol extinction), elevated layer (identifying elevated plumes, for example for biomass burning) and low extinction (representative of small aerosol extinction, such as vegetated, marine and arctic areas).

The high-resolution radiances emerging from the top of the atmosphere measurements are degraded to different spectral resolutions, simulating spectrometers with different resolving powers. We use optimal estimation theory to quantify the information content in the aerosol profile retrieval
\end{abstract}

with respect to different aerosol parameters and instrument spectral resolutions.

The simulations show that better spectral resolution generally leads to an increase in the total amount of information that can be retrieved, with the number of degrees of freedom (DoF) varying between $0.34-2.01$ at low resolution $\left(5 \mathrm{~cm}^{-1}\right)$ to $3.43-5.38$ at high resolution $\left(0.05 \mathrm{~cm}^{-1}\right)$ among all the different cases. A particularly strong improvement was found in the retrieval of tropospheric aerosol extinction profiles in the lowest $5 \mathrm{~km}$ of the atmosphere. At high spectral resolutions $\left(0.05 \mathrm{~cm}^{-1}\right), 1.18-1.48$ and $1.31-1.96$ DoF can be obtained in the lower $(0-2 \mathrm{~km})$ and middle $(2-5 \mathrm{~km})$ troposphere, respectively, for the different cases. Consequently, a separation of lower and mid tropospheric aerosols is possible, implying the feasibility of identification of elevated biomass burning aerosol plumes (elevated layer scenario). We find that a higher single scattering albedo (SSA) allows for the retrieval of more aerosol information. However, the dependence on SSA is weaker at higher spectral resolutions.

The vegetation (surface albedo 0.3), marine (surface albedo 0.05) and arctic (surface albedo 0.9) cases show that the dependence of DoF on the surface albedo decreases with higher resolution. At low resolution $\left(5 \mathrm{~cm}^{-1}\right)$, the DoF are 1.19 for the marine case, 0.73 for the vegetation case and 0.34 for the arctic case, but increase considerably at $0.05 \mathrm{~cm}^{-1}$ resolution to 3.84 (marine) and 3.43 (both vegetation and arctic), showing an improvement of a factor of 10 for the arctic case. Vegetation and arctic case also show the same DoF at higher resolution, showing that an increase of albedo beyond a certain value, i.e., 0.3 in our case, does not lead to a larger information content. 
The simulations also reveal a moderate dependence of information content on the integration time of the measurements, i.e., the noise of the spectra. However, our results indicate that a larger increase in DoF is obtained by an increase in spectral resolution despite lower signal-to-noise ratios.

\section{Introduction}

Atmospheric aerosols play a central role in the Earth's radiative budget. Together with various greenhouse gases, aerosols represent the most significant anthropogenic forcers responsible for climate change. However, uncertainties about the origin and composition of aerosol particles, their size distribution, concentration, spatial and temporal variability, make climate change prediction challenging. In order to quantify the influence of aerosols on the Earth's climate and to better validate climate models, information about their global abundance, properties and height distribution are needed.

Aerosol vertical and horizontal distribution significantly affects total radiative forcing in the Earth's troposphere and stratosphere. Aerosol particles transported by wind over long distances in the free troposphere affect climate on larger spatial scales than aerosols close to the surface. Those confined in the boundary layer (BL), have shorter lifetimes and have a more local impact on climate and air quality. Hence, knowledge of the vertical and horizontal distribution is crucial to understanding the impact of aerosols (Zarzycki and Bond, 2010; Koffi et al., 2012; Samset et al., 2013; Vuolo et al., 2014; Geddes and Bösch, 2015). Similarly, the climate impact through indirect effects, e.g., aerosol altering cloud microphysical properties, also depends strongly on the altitude of the aerosol (Hansen and Lacis, 1990).

To fully understand the impact of aerosols on a global scale, the use of passive satellite remote sensing observations has been shown to be extremely useful. Algorithms for aerosol and cloud retrieval, e.g. over land (Martonchik et al., 2009; Diner et al., 2012; Kalashnikova et al., 2013; Sanders et al., 2015) using MISR (Multi-angle Imaging SpectroRadiometer) data (Diner et al., 1989), and over the ocean (Duforêt et al., 2007; Dubuisson et al., 2009; Sanders et al., 2015) using the POLDER (Polarization and Directionality of the Earth's Reflectances) (Deschamps et al., 1994) and MERIS (Medium Resolution Imaging Spectrometer) (Rast et al., 1999) data, have been successfully developed in the last decade. Many of these instruments include a window around the spectrally unresolved $\mathrm{O}_{2}$ A-band.

Studies have shown how satellite measurements can be used to retrieve aerosol and cloud properties using the absorption and continuum part of the oxygen A-band (Fischer and Grassl, 1991; Gabella et al., 1999; Heidinger and Stephens, 2000; Rozanov and Kokhanovsky, 2004; Natraj et al., 2005; Boesche et al., 2008).
Multispectral high-resolution radiance and polarization measurements in the absorption spectrum of molecular $\mathrm{O}_{2}$ have been successfully used to retrieve the vertical distribution of aerosols and clouds (Hasekamp and Landgraf, 2007; Kokhanovsky and Rozanov, 2010; Sanghavi et al., 2012; Sanders and de Haan, 2013; Hollstein and Fischer, 2014; Geddes and Bösch, 2015).

$\mathrm{O}_{2}$ A-band data from the SCIAMACHY (Scanning Imaging Absorption Spectrometer for Atmospheric Chartography) (Bovensmann et al., 1999) instrument has shown that the retrieval of aerosol vertical distribution depends strongly on aerosol optical properties (single scattering albedo and phase function especially) and surface parameters (Corradini and Cervino, 2006).

Natraj et al. (2007) demonstrated that neglecting polarization in the forward modeling of $\mathrm{O}_{2} \mathrm{~A}$-band backscatter measurements from space-based instruments, can affect the retrieval precision in different ways for different atmospheric scenarios. They investigated errors resulting from ignoring polarization in retrievals for varying geometry, surface reflectance and aerosol loading, using simulated OCO (Orbiting Carbon Observatory) (Crisp et al., 2004) data.

Frankenberg et al. (2012) showed that the information content for both aerosols and trace gases can be improved by adding off-nadir viewing angles in hyperspectral measurements. They also investigated the dependence of the aerosol information content for different instrument specifications in multi-angle retrievals. Furthermore, over vegetated areas, chlorophyll fluorescence provides an additional contribution to the signal in the oxygen A-band (Sanders and de Haan, 2013). Investigation of this phenomenon (Frankenberg et al., 2011) demonstrates that the signal from atmospheric scattering is affected by this type of emission, and that neglecting it can cause systematic biases in the retrieval of aerosol parameters such as layer height and optical thickness, or surface properties such as surface pressure and albedo.

Sanghavi et al. (2012) used a combination of oxygen Aand B-band SCIAMACHY data to infer a complete vertical distribution of aerosols for a specific area in Kanpur (India).

Recently, Geddes and Bösch (2015) pointed out that the height and optical depth of aerosol layers can be properly retrieved from satellites using the $\mathrm{O}_{2}$ A-band only if the layers are close to the free troposphere. Their study shows that, while satellite observations can provide good information on aerosol plumes close to the free troposphere, information on boundary layer aerosols is still limited.

A concept study by Hollstein and Fischer (2014), investigated the role of instrument spectral resolution and noise on aerosol profile retrievals from $\mathrm{O}_{2}$ A-band measurements, using a forward operator based on look-up tables. They varied instrument resolution, signal-to-noise ratio, and spectral sampling, and performed optical depth and layer height retrievals for different aerosol types. Their results indicate that the retrieval generally benefits from improved spectral resolution, and strongly depends on the signal-to-noise level. 
The aim of this work is to evaluate the amount of vertical information on aerosol extinction profiles that can be extracted from satellite-based remote sensing measurements of the $\mathrm{O}_{2}$ A-band. Of particular interest is the impact of improvements in spectral resolution on the aerosol profile information content. To this end, we perform simulations of high resolution $\mathrm{O}_{2}$ A-band spectra as observed by a satellite instrument, and use optimal estimation theory to determine the amount of vertical information with respect to aerosol profile retrievals, and its dependence on spectral resolution and noise. Since our primary focus is the amount of aerosol information, we do not consider the effect of chlorophyll fluorescence in this work. Methods to quantify the chlorophyll fluorescence have been developed (Frankenberg et al., 2011), and we assume that its contribution can be independently assessed and corrected. By performing a detailed calculation and comparison of the information content retrieval for different altitude ranges (as opposed to the total columnar value that is typically reported), we investigate, for a variety of scenarios, if the tropospheric information can be isolated and evaluated.

The paper is organized as follows: Sect. 2 provides an overview of the atmospheric model and the a priori assumptions, along with a description of the radiative transfer (RT) calculation and the convolution for different instrument specifications. A description of the signal-to-noise model is also given for a better understanding of the results. Section 3 describes the theory behind the information content analysis and defines the quantities involved in the determination of the various retrieval metrics. Section 4 explains how the information content tests were performed, and compares the results for the different cases. Section 5 presents some concluding remarks.

\section{Radiative transfer simulations}

In order to test the sensitivity of different instrument specifications to aerosol retrievals, high resolution $\mathrm{O}_{2}$ A-band spectra simulated with a RT model (described below) were convolved with Gaussian instrument functions of different spectral resolutions. To investigate the effects of noise, we used modeled radiances, assumptions on the instrument response, and different integration times. These calculations were performed for different a priori aerosol profiles and covariances. This section will describe the RT calculation and the convolution.

\subsection{Atmospheric model}

The interpretation of remotely sensed data often requires radiative transfer models (RTMs) to simulate radiances and their analytic derivatives (Jacobians) with respect to various atmospheric and surface parameters.
A variety of RTMs have been developed over the years. Our choice of RTM was guided by the need to perform a large number of calculations to fully resolve the $\mathrm{O}_{2}$ A-band, provide an accurate description of the full Stokes vector, and have the ability to effectively calculate Jacobians with respect to various atmospheric parameters. With the above needs in mind, we chose VLIDORT as the RTM (Spurr, 2006). The VLIDORT model calculates all of the Stokes parameters in a multi-layer, multiple scattering medium. The model is also fully linearized; the advantage of this design is that an entire set of intensities and weighting functions required for an iteration step in a multi-parameter atmospheric retrieval can be generated simultaneously and in an analytic fashion, with a single call to the model, saving a significant amount of computing time. This feature makes the code ideally suited for retrieval applications, where computational time and memory requirements may represent a problem. A complete kernel-model Bidirectional Reflectance Distribution Function/Matrix (BRDF/M) set is also implemented for surface reflection and surface property weighting functions, including surface thermal emission (isotropic). VLIDORT is not internally linked with any databases for spectral optical properties and/or pre-computed look-up tables. The code uses a user-defined environment, where geophysical atmospheric inputs such as vertical profiles (thermal, trace gases and aerosol), optical parameters (single scattering albedo, asymmetry parameter, optical thickness, phase function moments) or spectral properties (cross sections, wavelengths), depend on the specific application and need to be defined by the user.

For this study, the atmosphere is divided into 60 layers, with a pressure range between $1001.6 \mathrm{mbar}$ (surface) and $0.3 \mathrm{mbar}$ (top of the atmosphere) and an altitude range between 0 and $55 \mathrm{~km}$. Vertical temperature and pressure profiles were based on the US Standard Atmosphere (NOAA, 1976) after an interpolation to a customized altitude grid. The vertical grid spacing has been set to $0.2 \mathrm{~km}$ in the $0-5 \mathrm{~km}$ range, $0.5 \mathrm{~km}$ in the $5-10 \mathrm{~km}$ range, and $1 \mathrm{~km}$ above $10 \mathrm{~km}$ altitude. The temperature, pressure, molecular, and aerosol properties are considered homogeneous within each layer. Molecular oxygen is the only absorber considered in this study. $\mathrm{O}_{2}$ spectral line parameters were taken from the $\mathrm{HI}-$ TRAN 2008 database (Rothman et al., 2009). Clouds were not considered and scattering is assumed to be caused by molecules and aerosols only. A Lambertian reflecting surface is assumed, with a surface albedo $a=[0.05,0.1,0.3,0.9]$, depending on the type of simulated atmospheric scenario. For a realistic satellite observation geometry, we assume four solar zenith angle $\mathrm{SZA}=\left[30,45,60,75^{\circ}\right]$ and an instrument looking down at nadir and $30^{\circ}$ off-nadir, with a fixed relative azimuth angle of $45^{\circ}$.

In this study, we consider the following four aerosol profiles, each representative of a different atmospheric scenario, to cover a variety of atmospheric/surface conditions (Fig. 1). 

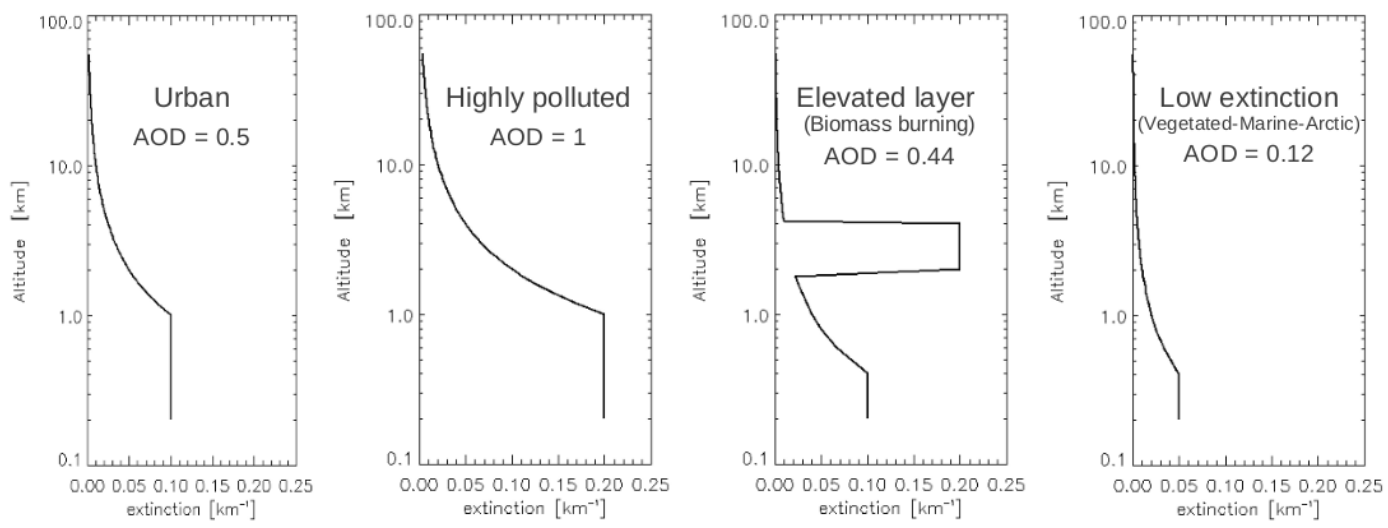

Figure 1. The four different aerosol profiles used in this study. From the left: urban $\left(k_{\mathrm{ext}}=0.1 \mathrm{~km}^{-1}, \mathrm{BLH}=1 \mathrm{~km}, \mathrm{AOD}=0.5\right)$, highly polluted $\left(k_{\mathrm{ext}}=0.2 \mathrm{~km}^{-1}, \mathrm{BLH}=1 \mathrm{~km}, \mathrm{AOD}=1\right)$, elevated layer $\left(k_{\mathrm{ext}}=0.2 \mathrm{~km}^{-1}\right.$, altitude range $\left.=2-4 \mathrm{~km}, \mathrm{AOD}=0.44\right)$, low extinction $\left(k_{\mathrm{ext}}=0.05 \mathrm{~km}^{-1}, \mathrm{BLH}=0.4 \mathrm{~km}, \mathrm{AOD}=0.12\right)$.

Urban - This profile reflects conditions in a moderately polluted urban or rural atmosphere, where high levels of aerosol are constrained to a well-defined boundary layer (Baidair et al., 2013; Schafer et al., 2014). The aerosol profile is thus constructed assuming a constant a priori aerosol extinction coefficient $k_{\mathrm{ext}}=0.1 \mathrm{~km}^{-1}$ below a fixed boundary layer height (BLH) of $1 \mathrm{~km}$, with a total aerosol optical depth AOD $=0.5$. Above the BL, extinction decreases exponentially with altitude (Wagner et al., 2011). A value of $a=0.1$ for the surface albedo has been adopted for this test case.

Highly polluted - For highly polluted urban areas such as megacities, the vertical profile shape is similar to that of the urban case, but the aerosol extinction in the boundary layer is higher (Clemer et al., 2010). We thus use the same parameterization as in the urban case, but with a larger extinction coefficient $k_{\mathrm{ext}}=0.2 \mathrm{~km}^{-1}$ $(\mathrm{AOD}=1)$ below a BLH of $1 \mathrm{~km}$.

Elevated layer - We considered a typical biomass burning plume to test the detection of aerosol layers in the free troposphere (Anderson et al., 1996; Ansmann et al., 2000; Wandinger et al., 2002; Johnson et al., 2008; Pelon et al., 2008; Matsui et al., 2010). The aerosol profile is confined to a layer between 2 and $4 \mathrm{~km}$ altitude with constant $k_{\mathrm{ext}}=0.2 \mathrm{~km}^{-1}(\mathrm{AOD}=0.44)$. BL aerosol extinction and height are set to $k_{\mathrm{ext}}=0.1 \mathrm{~km}^{-1}$ and $0.4 \mathrm{~km}$, respectively. Surface albedo is set to $a=$ 0.1 .

Low extinction - We also investigated a vegetation, marine and arctic case with lower aerosol extinction at the surface and a lower BLH. The arctic case is representative of an environment with pollution, often referred to as "arctic haze" (Shaw, 1995). We assume the same $k_{\text {ext }}$ and BLH for all cases to simulate the aerosol profile, changing the surface albedo in the respective en- vironment. Many studies have shown the great variability of extinction and BLH of aerosol in these environments (Blanchet and List, 1983; Leiterer et al., 1997; Quinn et al., 2002; Yamanouchi et al., 2005; Li et al., 2006; Diedenhoven et al., 2007; Yu et al., 2010; Frieß et al., 2011; Sayer et al., 2012; Tesche et al., 2014; Zhengjia et al., 2015). Consequently, these profiles are only meant to be representative of typical conditions. For all profiles we adopted a constant value of $k_{\mathrm{ext}}=0.05 \mathrm{~km}^{-1}$ (above the $\mathrm{BL}$, extinction decreases exponentially with altitude) and a BLH of $0.4 \mathrm{~km}(\mathrm{AOD}=0.12)$. In this case, surface albedo values of $a=0.05, a=0.3$ and $a=0.9$ have been adopted for the marine, vegetation and a snow-covered arctic scenario respectively.

It is worth mentioning that the adopted extinction profiles are not representative of any particular area or location on Earth. They only represent a plausible parameterization of the upper extinction limit for the different scenarios. Figure 1 shows the vertical profiles for all cases. A set of four single scattering albedos $\omega=[0.8,0.85,0.9,0.95]$, together with an asymmetry parameter $g=0.7$, were used for this test to describe the optical properties of the aerosol in the different cases (Dubovik et al., 2002; Quinn et al., 2002; Xia et al., 2006; Clemer et al., 2010; Baidair et al., 2013). The choice of $g=0.7$ for the asymmetry factor represents a reasonable value for all of the scenarios, especially since the results of our analysis do not strongly depend on $g$.

\subsection{High resolution spectra and convolution}

VLIDORT was used to generate oxygen A-band high resolution radiance spectra $L_{\mathrm{h}}\left(v_{0}\right)$ in the spectral range $\Delta=12950-13200 \mathrm{~cm}^{-1}(757-772 \mathrm{~nm})$, with a fixed spectral sampling $\Delta v_{0}=0.002 \mathrm{~cm}^{-1}$ and a number of points given by $v_{0}=\Delta / \Delta v_{0}=125000$. At this high resolution, all 

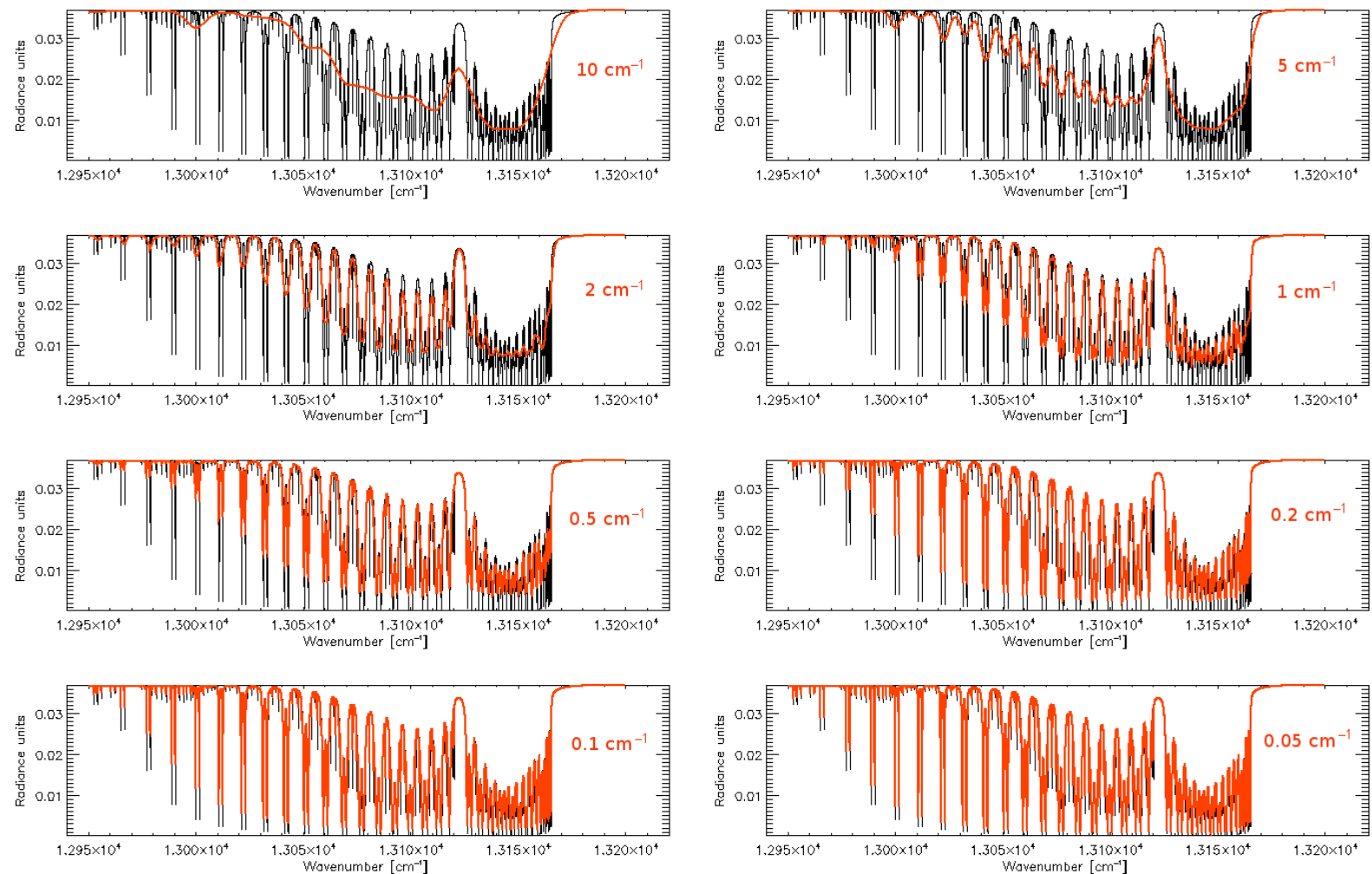

Figure 2. Example of $\mathrm{O}_{2}$ A-band high resolution spectrum $\Delta v_{0}=0.002 \mathrm{~cm}^{-1}$ (black line) convolved with eight different instrument function FWHM (red line).

of the spectral features of the oxygen A-band are fully resolved.

To simulate the measurement of the $\mathrm{O}_{2} \mathrm{~A}$-band by a spaceborne spectrometer, Gaussian instrument response functions for different full widths at half maximum (FWHM) were calculated. The high resolution $\mathrm{O}_{2}$ spectra were then convolved with this function. The convolved spectrum was then down-sampled by integrating the radiances over a grid point of width $\Delta v$. We chose to keep the ratio of FWHM to $\Delta v$ constant at 5 , to avoid under or oversampling of the spectrum during the convolution. Therefore, when we increased the instrument resolution (decreasing FWHM), we decreased $\Delta v$ accordingly:

$$
\frac{\mathrm{FWHM}}{\Delta v}=5 \text {. }
$$

The Gaussian function representing the instrumental response is described as

$G\left(v^{\prime}, \mathrm{FWHM}\right)=\frac{1}{\sigma \sqrt{2 \pi}} \cdot \exp \left[-\frac{v^{\prime 2}}{2 \sigma^{2}}\right]$

with $\sigma$ defined as

$\sigma=\frac{\text { FWHM }}{2 \sqrt{2 \ln 2}}$ where the first factor in Eq. (2) takes into account the normalization of the area of the function $G\left(v^{\prime}, \mathrm{FWHM}\right)$ to 1 , and $v^{\prime}$ represents the Gaussian spectral sampling extended to \pm 5 FWHM for each spectral channel.

The spectral radiance (the term radiance refers to the directional spectral intensity in frequency units $\left[\mathrm{W} \mathrm{m}^{-2} \mathrm{sr}^{-1} \mathrm{~cm}\right]$ ) is the result of the convolution of the simulated high resolution radiance with the instrument spectral response function (each channel is assumed to be independent of the others). The convolved radiance $L_{\mathrm{c}}$ is expressed as

$L_{\mathrm{c}}(v)=\sum_{v^{\prime}} L_{\mathrm{h}}\left(v^{\prime}\right) G\left(v^{\prime}-v\right) \Delta v$,

calculated as the sum over the instrument response function spectral sampling $v^{\prime}$, of the product of the spectral response function and the high resolution radiance $L_{\mathrm{h}}$, expressed over the set of frequencies $v^{\prime}$. The index $v=\Delta / \Delta v$ for each instrument channel represents the chosen sampling grid covering the entire spectral range $\Delta$. Figure 2 shows an example of the high resolution spectrum $\left(\Delta v_{0}=0.002 \mathrm{~cm}^{-1}\right)$ convolved with different instrument function FWHM. For high resolution the narrow absorption features are well described, allowing a better retrieval of aerosol information. 


\subsection{Noise model}

The instrument noise model assumes that measurement noise is dominated by photon shot noise. Shot noise comes from the statistical uncertainty of the number of photons sampled by the detector, which can be described by a Poisson distribution. This assumption is quite accurate for modern spectrometers. Based on Poisson statistics we calculate the standard deviation of the radiance measurement $\sigma_{\mathrm{m}}$ as follows:

$\sigma_{\mathrm{m}}=\sqrt{N}$

with relative signal-to-noise ratio (SNR) proportional to the square root of the number of photons $N$ :

$\mathrm{SNR}=\frac{N}{\sigma_{\mathrm{m}}}=\sqrt{N}$.

The measurement error is thus proportional to the standard deviation $\sigma_{\mathrm{m}}$ (which can be calculated as the square root of $N$ ) with a relative variance $\sigma_{\mathrm{m}}^{2}$. To calculate the number of photons $N$ falling on the detector, we use the following expression:

$N=\frac{L_{\mathrm{c}}(v) \cdot \Delta t \cdot \epsilon \cdot \Omega \cdot A}{E_{\mathrm{ph}}} \cdot \Delta v$,

where $E_{\mathrm{ph}}$ is the energy of a photon at $13150 \mathrm{~cm}^{-1}(760 \mathrm{~nm})$, $\Delta t$ is the integration time, $\epsilon$ is the efficiency of the spectrometer/detector combination, $\Omega$ is the solid angle of the field of view of the instrument and $A$ is the slit surface area. For our calculations we use $E_{\mathrm{ph}}=2.6 \times 10^{-19} \mathrm{~J}$ photon $^{-1}, \epsilon=0.05$, $\Omega=0.01$ steradians, $A=5.0 \times 10^{-7} \mathrm{~m}^{2}$.

We implemented this noise model without considering any particular design or instrument specifications. Signalto-noise ratios (SNR) outside of the A-band, i.e., at $13190 \mathrm{~cm}^{-1}$, for a $\Delta t=1 \mathrm{~s}$ varies from 5000 at the lowest resolution to 500 at the highest resolution. These SNR values are higher than those of current satellite instruments, but in the range of high quality future instruments. We also analyze the sensitivity of our simulations to noise by varying the integration time between 0.1 and $5 \mathrm{~s}$. The sensitivity of the model to the radiance level (which depends on resolution), and to the integration time, allows us to evaluate the capability of different sensors to retrieve information for different aerosol scenarios.

\section{Information content analysis}

To determine the information content of an aerosol retrieval based on the spectroscopic observations in the $\mathrm{O}_{2} \mathrm{~A}$-band at different resolutions, we use an optimal estimation formalism, as described in detail in Rodgers (Rodgers, 2000).

An atmospheric state vector $\boldsymbol{x}$, containing the parameters of interest, is related to a measurements vector $\boldsymbol{y}$, through a forward model $\boldsymbol{F}(\boldsymbol{x}, \boldsymbol{b})$, which is a function of $\boldsymbol{x}$ and other model parameters not retrieved (vector $\boldsymbol{b}$ ):

$y=F(x, b)+\epsilon$,

where $\boldsymbol{\epsilon}$ is the measurements error vector (e.g., instrument noise). For atmospheric remote sensing retrievals, $\boldsymbol{F}(\boldsymbol{x}, \boldsymbol{b})$ is normally a radiative transfer model.

The solution to the inverse problem is then to use the forward model and the information from the measurement vector $\boldsymbol{y}$ to construct an estimate of the atmospheric state. For an inverse problem, the a priori state vector $\boldsymbol{x}_{\mathrm{a}}$ is often used as an initial estimate. $\boldsymbol{x}_{\mathrm{a}}$ is ideally chosen to be close to the true state $\boldsymbol{x}$, based on existing knowledge of the atmosphere. Because of the nonlinear nature of the dependence of the model on the true state vector (and the real measurements), the solution for a full retrieval of the retrieved state vector, $\hat{\boldsymbol{x}}$, has to be found using an iterative process, which ends when an optimal agreement between the model $\boldsymbol{F}(\boldsymbol{x}, \boldsymbol{b})$ and the real measurements vector $\boldsymbol{y}$ is reached. Such an approach, however, requires a good knowledge of the properties of the parameters involved in the measurements (aerosol micro-physical and optical properties, spectroscopic parameters, model uncertainties, surface properties) and the relative errors for every measurement (instrument noise).

Here we are interested in a theoretical and more general quantification of the aerosol retrieval information content for different scenarios, with no reference to any specific mission, instrument or location, we perform a one-step retrieval instead, assuming the a priori parameters to be known and a linear dependence of the forward model $\boldsymbol{F}(\boldsymbol{x}, \boldsymbol{b})$ on the state vector $\boldsymbol{x}$. The forward model is directly applied to our first guess (linear regime), assumed to be the true state, for which we define an a priori uncertainty. We then derive the corresponding information content, calculated using the optimal estimation method. We remark that this methodology is not applicable for retrieval with real data, where the high nonlinearity of the physical process and the imperfect knowledge of the a priori parameters requires the use of an iterative approach.

According to the Bayesian formalism, the linearization of the forward model about the state vector can be expressed as

$\boldsymbol{y}=\mathbf{K} \boldsymbol{x}+\boldsymbol{\epsilon}$,

where $\mathbf{K}$ is the functional derivative matrix, also called Jacobian, which represents the change in the measurement for a unit change in the retrieved parameter.

For this study, the vertical aerosol extinction profile represents the retrieved parameter, $\boldsymbol{x}$, and the elements of $\mathbf{K}$ represent the derivative of the radiance with respect to the aerosol extinction coefficients, for every single layer and every single wavenumber. VLIDORT provides analytic derivatives of the Stokes vector field with respect to any atmospheric or surface property (Spurr, 2006). The Jacobians required in Eq. (9) can be calculated from these weighting functions by the application of the chain rule. For every scenario, we fix the model 
parameters, calculating the radiance and the Jacobian with a single run of the code, before using these quantities for the estimation analysis.

The sensitivity of the retrieval of a set of parameters, to the measurement, is expressed by the so-called gain matrix $\mathbf{G}$ :

$\mathbf{G}=\left(\mathbf{K}^{T} \mathbf{S}_{\epsilon}^{-1} \mathbf{K}+\mathbf{S}_{\mathrm{a}}^{-1}\right)^{-1} \mathbf{K}^{T} \mathbf{S}_{\epsilon}^{-1}$

An important part of optimal estimation analysis is the covariance matrix, $\mathbf{S}_{\mathrm{a}}$, which quantifies the uncertainty in our knowledge of the retrieved parameter prior to the measurement, and the measurement error covariance matrix, $\mathbf{S}_{\epsilon}$, which quantifies the error of the measurement. We calculate $\mathbf{S}_{\epsilon}$ according to the instrument noise model described in Eqs. (5)-(7). We will discuss the choice of $\mathbf{S}_{\mathrm{a}}$ further below. We assume both matrices to be diagonal, with all of the off-diagonal elements equal to zero. Every element of the diagonal thus represents the variance of the respective element in the a priori parameter and the measurement vector, respectively. We assume the errors to be uncorrelated.

The sensitivity of the retrieval to the true state of the parameter is expressed by the Averaging Kernel (AK) matrix A:

$\mathbf{A}=\mathbf{G K}$

which is equal to a unit matrix for an ideal retrieval, when a perfect match between the a priori and the retrieved parameter is achieved. The trace of $\mathbf{A}$ represents the number of degrees of freedom (DoF), which represent the total number of independent pieces of information derived by the retrieval. Combining Eqs. (11) and (10), the averaging kernel matrix $\mathbf{A}$ can be written as

$\mathbf{A}=\left(\mathbf{K}^{T} \mathbf{S}_{\epsilon}^{-1} \mathbf{K}+\mathbf{S}_{\mathrm{a}}^{-1}\right)^{-1} \mathbf{K}^{T} \mathbf{S}_{\epsilon}^{-1} \mathbf{K}$

which shows the dependence of DoF on the $\mathbf{S}_{\mathrm{a}}, \mathbf{S}_{\epsilon}$ and $\mathbf{K}$ matrices.

The AK can be seen as a linear representation of the information content of the retrieval parameters. It represents the relationship of the retrieval to the true state vector, and ranges between 0 and 1 . An AK close to 1 means that a nearperfect agreement between the retrieved parameter and the true state has been reached. As it represents an indication of what the measurement is sensitive to, the AK can also be interpreted as the vertical resolution of the retrieval, because it provides important information on the vertical sensitivity of the instrument, with its maximum corresponding to the range of altitudes where the maximum sensitivity occurs.

A sample AK is shown in Fig. 3, where four different regions of the atmosphere are color-coded. In this case, the region between 2 and $5 \mathrm{~km}$ represents the altitude range with the highest sensitivity to aerosol extinction.

Based on this formalism we perform three different sensitivity studies. In the first, we investigate the dependence of the DoF on the observation geometry, varying both solar and
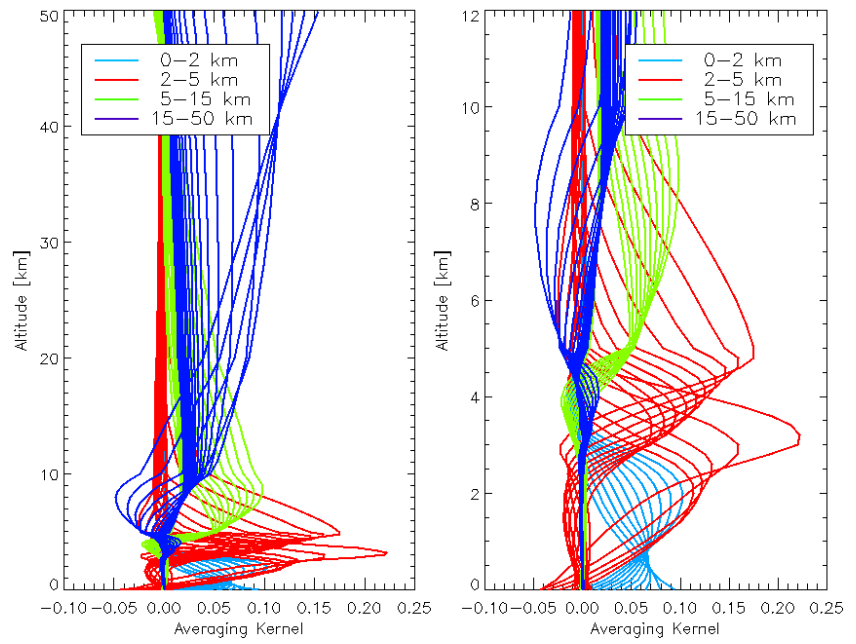

Figure 3. Example of averaging kernel vs. altitude. The simulation refers to a convolved spectrum of spectral resolution $\Delta v=0.01 \mathrm{~cm}^{-1}$ and FWHM $=0.05 \mathrm{~cm}^{-1}$ with a solar zenith angle $\mathrm{SZA}=45^{\circ}$ and an instrument viewing angle of $30^{\circ}$ off-nadir. The $\mathrm{AK}$ are color-coded for different altitude ranges. On the right, a zoom between 0 and $12 \mathrm{~km}$ is shown.

viewing angle. In the second test, we study the effect of instrument resolution by varying the FWHM and $\Delta v$ (Eq. 1), and scale the relative noise $\sigma_{\mathrm{m}}$ according to the radiances at the various spectral resolutions; i.e., at higher spectral resolution fewer photons are sampled per channel, resulting in larger relative errors and vice versa. It should be noted that the number of channels is also varied in this test, as discussed previously. In the final test, we keep the instrument resolution constant and only vary the relative noise by changing the integration time $\Delta t$ in Eq. (7). This calculation serves to better understand the contribution of the change in per-channel noise with resolution to the information content.

We thus investigate the dependence of the degrees of freedom of the retrieved aerosol extinction profile on different instrument spectral resolution FWHM (and relative spectral binning $\Delta v$ ) and different integration time $\Delta t$. We also perform the second and third test for different a priori aerosol extinction profile errors, expressed through the $\mathbf{S}_{\mathrm{a}}$ matrix in Eq. (10), to investigate the influence of prior knowledge of the aerosol extinction. We assume that the diagonal elements of $\mathbf{S}_{\mathrm{a}}$, which represent the a priori extinction profile variances for every single layer, are constant at all altitudes.

Six different a priori variances are used: $0.7,0.5,0.2,0.1$, $0.05,0.01$, which correspond to a relative error of $83.7,70.7$, $44.7,31.6,22.4$ and $10.0 \%$ of the a priori aerosol extinction profile, respectively. It should be noted that performing this sensitivity calculation is very important, as the total pieces of information of a system strongly depend on the a priori knowledge of the retrieval parameter, as we will discuss in the following section. 

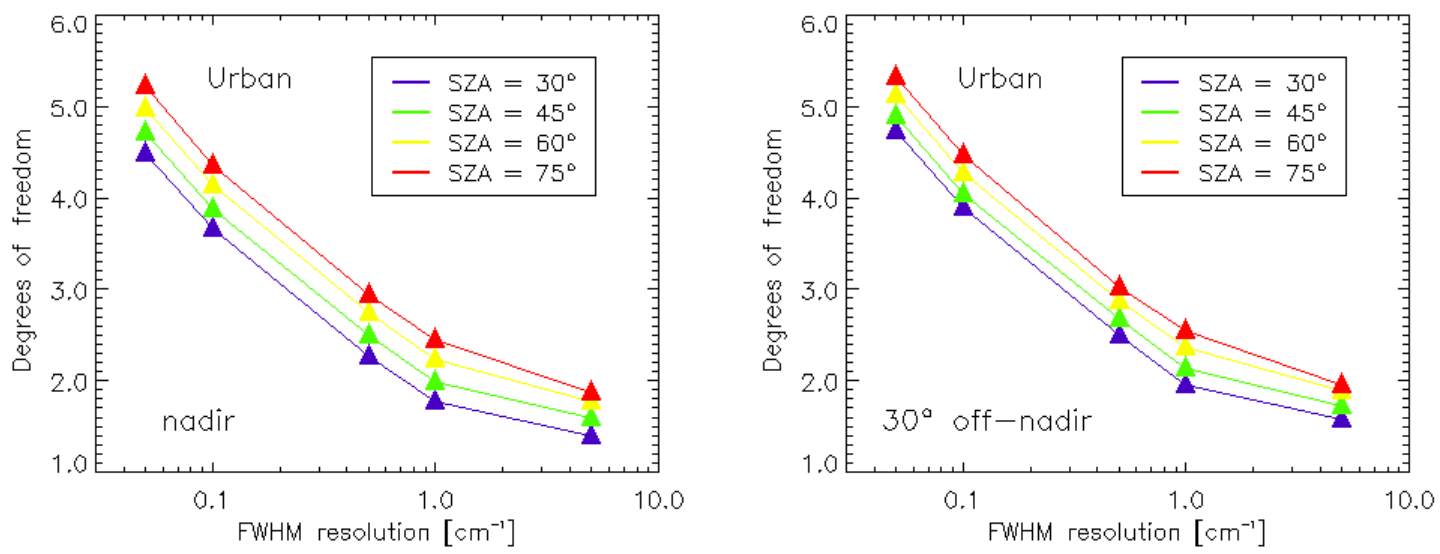

Figure 4. Nadir and $30^{\circ}$ off-nadir urban scenario total degrees of freedom for different instrument resolution and four different solar zenith angle $\left(30,45,60,75^{\circ}\right)$.

\section{Results and discussion}

\subsection{Resolution sensitivity}

In order to understand the impact of different instrument resolutions on the total amount of information available, we perform calculations for five pairs of values of FWHM and $\Delta v$ : $\mathrm{FWHM}=(5,1,0.5,0.1,0.05) \mathrm{cm}^{-1}$ and $\Delta v=(1,0.2,0.1$, $0.02,0.01) \mathrm{cm}^{-1}$. Tables showing the numerical values of the DoF for the complete set of resolutions can be found in the Supplement.

Using the relationships previously described, we calculate the total DoF for every pair of these values.

All DoF values are calculated in the spectral range from $13122 \mathrm{~cm}^{-1}$, where weak or small absorptions occur, to the main absorption frequencies around $13140 \mathrm{~cm}^{-1}$. This range is able to account for almost the entire content of information available in the main absorption band $13122-13170 \mathrm{~cm}^{-1}$, because of the strong dynamics of the atmospheric absorption in that range. An initial test with a wider spectral range (not described or shown in the manuscript), covering the main absorption band, showed that the DoF were similar (few percent higher) when compared with the range used in this work. The reason for using a small wavenumber window was the long computational time needed for all the simulations. The DoF evaluation requires the simulation of high resolution radiance spectra (and relative Jacobian matrices) at $0.002 \mathrm{~cm}^{-1}$, and the convolution at different resolution for every single geometry and every single scenarios. In the end, the chosen spectral range represents a good compromise between the computational time and the marginal loss of information.

An integration time of $\Delta t=1 \mathrm{~s}$ has been used for the tests. The a priori knowledge of the aerosol profile is constrained by the covariance matrices $\mathbf{S}_{\mathrm{a}}$.

In order to explore the dependence of DoF on observation geometry, we vary the SZA $\left(30,45,60\right.$ and $\left.75^{\circ}\right)$ and the viewing angle (nadir and $30^{\circ}$ off-nadir) for a fixed relative azimuth angle $\left(45^{\circ}\right)$, implementing the urban scenario for the aerosol and assuming $\omega=0.95$ as single scattering albedo. Figure 4 shows the improvement of the information content due to resolution and higher values of SZA, for both observations. A different solar illumination changes the scattering angle of the particles, allowing a better information retrieval. At $5 \mathrm{~cm}^{-1}$ resolution, DoF improve from $1.39\left(\mathrm{SZA}=30^{\circ}\right)$ to $1.87\left(\mathrm{SZA}=75^{\circ}\right)$ and from 4.49 to 5.22 (same $\left.\mathrm{SZA}\right)$ at $0.05 \mathrm{~cm}^{-1}$, for the nadir case. The same change in resolution for the $30^{\circ}$ off-nadir viewing angle allows a similar improvement in the DoF with a change from $1.57\left(\mathrm{SZA}=30^{\circ}\right)$ to $1.96\left(\mathrm{SZA}=75^{\circ}\right)$ at lower resolution and from 4.74 to 5.33 at $0.05 \mathrm{~cm}^{-1}$ resolution, for the same solar angles. As expected, the off-nadir viewing angle shows higher absolute DoF due to the longer light path.

We investigate the effect of different $\mathbf{S}_{\mathrm{a}}$ on the total DoF for the highly polluted aerosol scenario, with $\omega=0.85$ and a nadir looking geometry with a $\mathrm{SZA}=45^{\circ}$. Figure 5a shows that increasing the resolution increases the amount of information available for the aerosol extinction profile retrieval. This is true for every a priori value of the diagonal elements of $\mathbf{S}_{\mathrm{a}}$, i.e., the a priori aerosol extinction profile relative errors.

A change in the resolution of 2 orders of magnitude (i.e., FWHM from 5 to $0.05 \mathrm{~cm}^{-1}$ ) leads to a three times (or more) increase in the DoF for all of the covariance values, showing the importance of fully resolving the narrow features of the band. On the other hand, the DoF decreases as the a priori knowledge (smaller relative error) of the retrieval parameter increases. This is due to the nature of optimal estimation: a better a priori knowledge of the parameter to be retrieved reduces the amount of information that can be obtained from the measurement.

While the extreme values of $\mathbf{S}_{\mathrm{a}}$ (aerosol relative errors of 83.7 and $10.0 \%$ respectively) are not very realistic, we implement them in this test to take into account a wider 

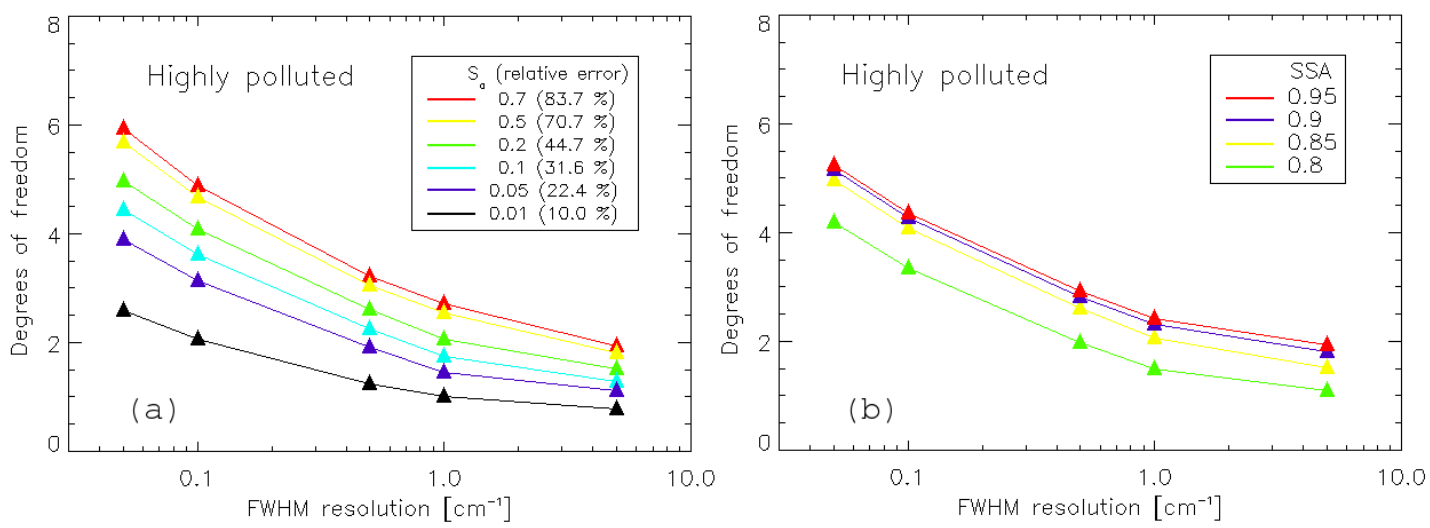

Figure 5. Highly polluted scenario total degrees of freedom for different aerosol extinction profile uncertainties $\mathbf{S}_{\mathrm{a}}(\mathbf{a})$. Degrees of freedom four values of single scattering albedo $\omega=[0.8,0.85,0.9,0.95]$, to simulate different type of aerosol, are shown in (b). SZA $=45^{\circ}$ and a nadir instrument viewing have been used.

set of possible aerosol conditions. For the rest of the tests, we choose a fixed value of $\mathbf{S}_{\mathrm{a}}=0.2$ (44.7\% relative error), which represents a reasonable choice of average aerosol uncertainties for the different profiles.

We also analyze the impact of different single scattering albedos on the DoF for the same scenario (Fig. 5b). At low spectral resolutions the DoF increases with an increase in $\omega$. This is due to the larger scattered radiance from the aerosol at higher $\omega$, which increases the signal, as well as the contrast to the surface. The DoF increase from a $\omega$ of 0.8 to 0.95 is a factor of 1.76 at low resolution. The DoF also increases with resolution (lower values of $\Delta v$ and FWHM) for all $\omega$. Interestingly, however, the effect of the single scattering albedo is significantly reduced at higher spectral resolutions. The DoF improvement from a $\omega$ of 0.8 to 0.95 is only a factor of 1.25 . It thus appears that resolving spectral features decreases the dependence of the retrieval on $\omega$. This reduction is likely due to the fact that the retrieval at high spectral resolution extracts information based on the $\mathrm{O}_{2}$ band shape, rather than the radiances alone. It should be noted that increasing $\omega$ further does not considerably change the results of the tests, as can already be seen in Fig. 5b, where the dependence of DoF on $\omega$ decreases with increasing $\omega$.

For the rest of this study we will use a fixed viewing geometry of $30^{\circ}$ off-nadir and SZA $=45^{\circ}$, with $\omega=0.95$. With $\omega, \mathbf{S}_{\mathrm{a}}$ and the observation geometry fixed, we can now analyze the dependence of the DoF on spectral resolution for the various aerosol profiles (Fig. 6).

In the urban and highly polluted scenarios, the DoF increases from 1.7 and 2 at $5 \mathrm{~cm}^{-1}$ resolution to $4.9-5.4$ at $0.05 \mathrm{~cm}^{-1}$ resolution respectively. The DoF improvement with spectral resolution is of a factor of 2.8 for the urban case and of 2.7 for the high polluted case. In general, the high polluted case has a $10-15 \%$ higher DoF due to its higher BL aerosol extinction.

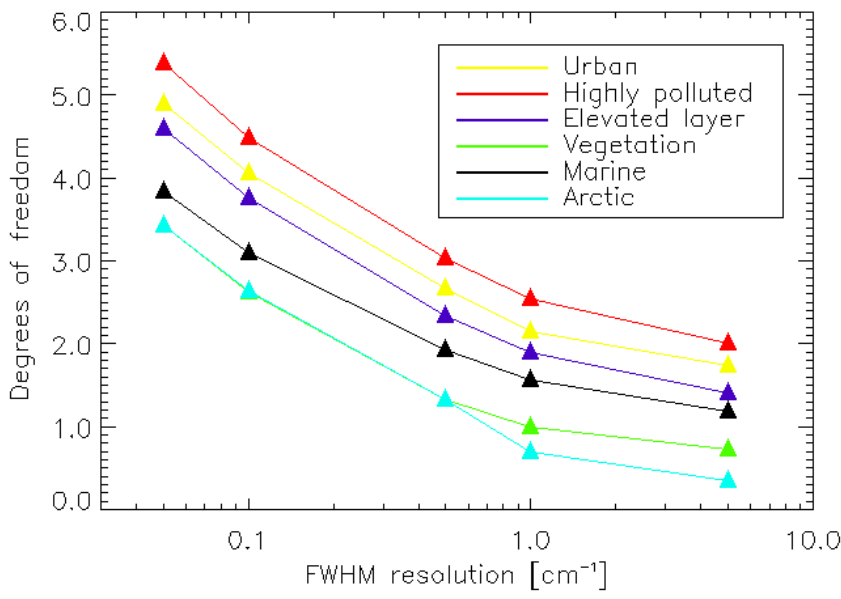

Figure 6. DoF comparison for the different aerosol scenarios. $\mathbf{S}_{\mathrm{a}}=0.2$ (44.7\% relative error) and $\omega=0.95$ for the a priori aerosol extinction profile uncertainty and single scattering albedo are assumed. SZA $=45^{\circ}$ and a $30^{\circ}$ off-nadir instrument viewing geometry have been used in all the tests.

The DoF for the elevated layer scenario are smaller than those in the urban polluted scenarios, changing from 1.4 to 4.6 as the resolution varies from 5 to $0.05 \mathrm{~cm}^{-1}$. The change in resolution for an aerosol layer between 2 and $4 \mathrm{~km}$ provides an improvement in the DoF of a factor of 3.3. It is evident that spectral resolution has a stronger impact on DoF for the elevated layer scenario than for the urban polluted scenario.

As expected, DoF in the vegetation, marine and arctic scenario are lower than in the previous cases, due to the generally lower aerosol extinction. At $5 \mathrm{~cm}^{-1}$ resolution, only the marine scenario allows the retrieval of pieces of information greater than unity, where for both vegetation and arctic case no information is available at this resolution. At $0.05 \mathrm{~cm}^{-1}$, 3.84 pieces of information can be retrieved for the marine 
scenario and 3.43 for both vegetation and arctic case. Again, the low-to-high resolution change leads to an improvement in the DoF of a factor of 3.2 (marine), 4.7 (vegetation) and 10 (arctic).

As the aerosol extinction profile is the same in the vegetation, marine and arctic scenarios, the difference in DoF among these three cases can be attributed to a surface albedo effect. The higher albedo in the arctic case leads to lower DoF, in particular for lower spectral resolutions. In fact, at low resolutions, almost no information $(\mathrm{DoF}=0.34)$ can be retrieved. However, higher spectral resolutions lead to a DoF improvement of a factor of 10 , and the $\mathrm{DoF}$ at a resolution of $0.05 \mathrm{~cm}^{-1}$ is only $10 \%$ lower than in the marine case. Similarly, the vegetation case shows the number of pieces of information is below 1 at $5 \mathrm{~cm}^{-1}$ and improves to 3.43 at higher resolution. The dependence of the content of information on surface albedo for the vegetation, marine and arctic scenarios is clearly visible in Fig. 6. where the vegetation and arctic scenario show the same DoF at $0.5 \mathrm{~cm}^{-1}$ spectral resolution.

The retrieval results are thus independent of albedos above 0.3 . The likely explanation is that above a certain threshold, backscattered radiation from the surface dominates over that from the aerosol and all the information comes from the $\mathrm{O}_{2}$ absorption rather than the intensity contrast between surface and aerosol.

High spectral resolution thus seems to be crucial for aerosol retrievals over medium and high surface albedo areas. The poor retrievals at low resolution over snow are due to the well-known problem of distinguishing highly scattering aerosol over a high albedo surface. The lack of contrast makes it impossible for a radiance-based retrieval to determine the aerosol extinction profile or even the column. In the marine case, where the albedo is 0.05 , the total DoF at low resolution is 1.19 , indicating that a total atmospheric aerosol optical depth can be retrieved. The vegetation scenario allows the same retrieval with a $\mathrm{DoF}=1$ at $1 \mathrm{~cm}^{-1}$ resolution. In the arctic case however, the total DoF is only 0.34 for low resolution and 0.7 at $1 \mathrm{~cm}^{-1}$ resolution, making it difficult to even retrieve a column value. On the other hand, since the retrievals at high spectral resolutions use information from the $\mathrm{O}_{2}$ absorption band centers and wings, they are partially based on radiances that do not penetrate all the way to the surface. There is, therefore, less sensitivity to surface properties.

\subsection{Altitude sensitivity}

The total DoF provides information about the total column. On the other hand, the AK matrix contains information related to the atmospheric layers; therefore, a calculation of subsets of the matrix $\mathbf{A}$ (and hence subsets of the Trace $[\mathbf{A}]=$ DoF) allows for an evaluation of the DoF, and its dependence on spectral resolution, for different altitude ranges. In order to get a better understanding of the altitude with maximum amount of information for the dif- ferent scenarios, we divide the atmosphere in four altitude regions: $\mathrm{I}=[0-2] \mathrm{km}, \mathrm{II}=[2-5] \mathrm{km}, \mathrm{III}=[5-15] \mathrm{km}$, IV $=[15-50] \mathrm{km}$, i.e., I and II for the lower and midtroposphere, III for the upper troposphere/lower stratosphere, and IV for the stratosphere. Figure 3 shows the color-coded AK for the four regions for a generic simulation. The results of the altitude-resolved DoF, and its dependence on spectral resolution for the different scenarios are reported in Fig. 7af. In all scenarios, an improvement in the DoF in the different altitude intervals is observed. This follows the general trend already observed in the whole-atmosphere DoF. However, the improvement of information with improving spectral resolution is not uniform with altitude.

In the urban and highly polluted scenarios (panel $\mathrm{a}$ and $\mathrm{b}$ respectively), the stratospheric DoF increases from 0.64 and 0.8 to 1.05 and 1.19 , respectively, as the spectral resolution increases from 0.5 to $0.05 \mathrm{~cm}^{-1}$. This change in DoF is smaller than that observed in the lower and mid-troposphere, where the increase is a factor of 4.2 and 3, respectively. In fact, for both regions, the DoF is below 1 for the lowresolution case and increases to values of 1.4-2 for the high resolution case. While the highly polluted scenarios requires a resolution of $F W H M=0.1 \mathrm{~cm}^{-1}$ to reach a DoF greater than 1 in the lower and mid-troposphere, the urban scenario requires the full resolution to achieve the same result. It is evident that a high spectral resolution is crucial for tropospheric aerosol extinction retrievals. At high resolution (FWHM $=0.05 \mathrm{~cm}^{-1}$ ), almost $65 \%$ (urban) and $64 \%$ (highly polluted) of the total DoF comes from Regions I and II.

The impact of spectral resolution on tropospheric aerosol retrievals is even more obvious in the elevated layer scenario. In this case a resolution of FWHM $=0.05 \mathrm{~cm}^{-1}$ is required to reach a DoF greater than 1 in Regions I and II (panel c). At this resolution, almost $60 \%$ of the total DoF originates from the lowest $5 \mathrm{~km}$ of the atmosphere with a DoF of 2.73 in this region (sum of DoF in region I and II). The improvement in the information content at higher resolutions is even clearer in this scenario, with a factor of 8.5 and 5.6 increase in DoF in Regions I and II, respectively. It should also be noted that, at higher resolutions, it is possible to retrieve an elevated aerosol layer above the BL (see profile in Fig. 1).

The vegetation, marine and arctic scenario results (panel $\mathrm{d}$, e and f respectively) agree with the previous tests. A resolution of FWHM $=0.05 \mathrm{~cm}^{-1}$ is needed to achieve DoF greater than 1 in the lower and mid-troposphere. The total number of DoF for the tropospheric levels (sum of Regions I and II) at FWHM $=0.05 \mathrm{~cm}^{-1}$ resolution is 2.72 (79\% of the total) for the vegetation case, 2.54 (66\% of the total) for the marine case and 2.49 ( $73 \%$ of the total) for the arctic scenario. The improvement in DoF with resolution is most pronounced in the arctic case, where DoF in Region I and II are below 0.1 and increase by a factor of 59 at high resolution.

It is worth mentioning again that the high resolution retrievals substantially reduce the albedo effect of the retrieval. 

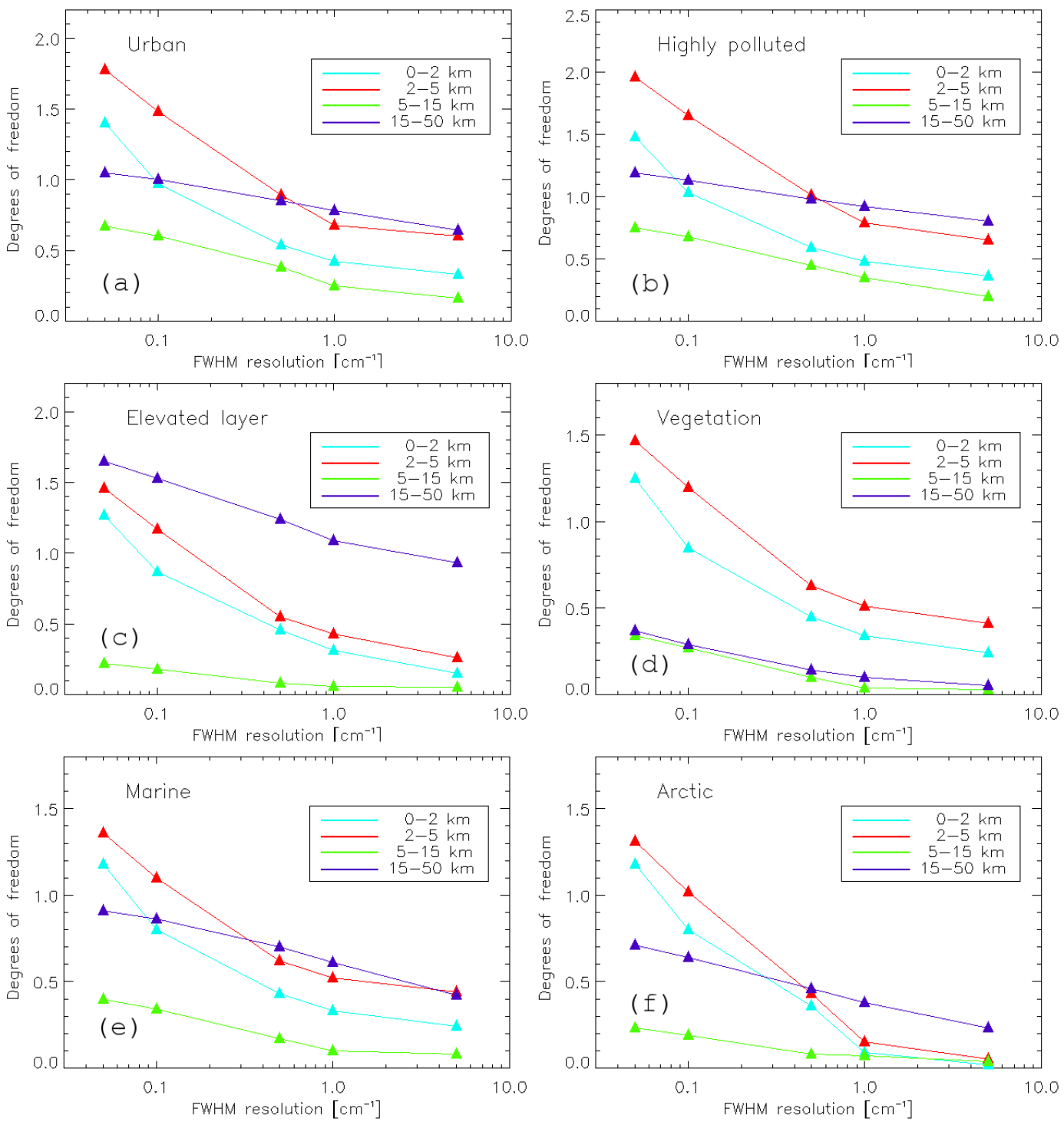

Figure 7. DoF calculated for four different altitude ranges to enhance the tropospheric contribution with respect to the whole atmosphere for every single aerosol scenario are shown in (a-f).

In particular, in the lower and mid-troposphere, there is no difference in the DoF at high resolutions. Again, this implies that the retrieval is dominated by the information in the $\mathrm{O}_{2}$ absorption bands, and in particular in the band wings, which allow probing different altitudes in the atmosphere without relying on reflected radiances from the surface.

\subsection{Integration time sensitivity}

Here we analyze the effects of different integration times (i.e., the effect of sampling noise) $\Delta t$ on DoF, investigating the dependence due to the change in photon noise in two different tests. The first test is a comparison among the same six different a priori aerosol uncertainties used for the resolution test (Fig. 5a), keeping the spectral resolution constant, with fixed values of FWHM $=0.1 \mathrm{~cm}^{-1}$ and $\Delta v=0.02 \mathrm{~cm}^{-1}$, and with $\omega=0.95$. The second test is a comparison among the same values of spectral resolutions used for all the previous calculations. In this last test, we keep the a priori aerosol uncertainty fixed to $\mathbf{S}_{\mathrm{a}}=0.2$ (44.7\% relative error), varying instrumental FWHM to investigate how photon noise affects the dependence of the content of aerosol information on the resolution. Six different integration times $\Delta t$ (ranging among $5,2,1,0.5,0.2$ and $0.1 \mathrm{~s}$ ) have been used for these two tests.

In the first test, the effect of the aerosol uncertainties on the content of information is investigated for different integration times. When the spectral resolution is fixed, Eq. (7) shows that the noise depends only on the variation of the integration time (all the other quantities are fixed). Integration time, however, is related to the covariance matrix $\mathbf{S}_{\epsilon}$ 

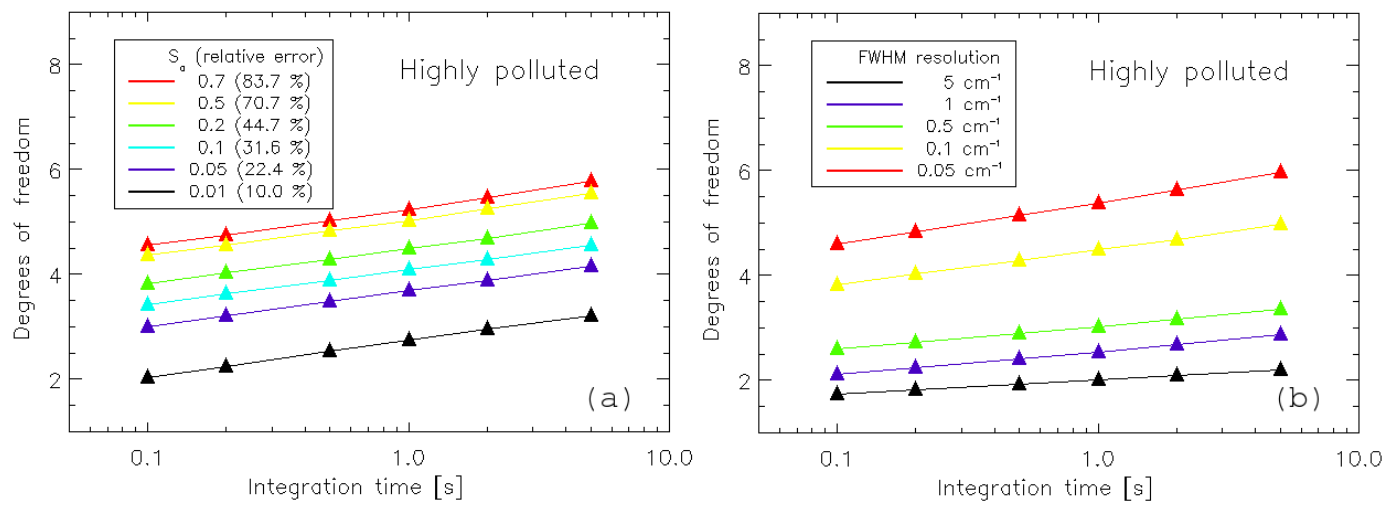

Figure 8. Integration time sensitivity for highly polluted scenario for different $\mathbf{S}_{\mathrm{a}}(\mathbf{a})$, and different spectral resolution (b).

through its dependence on the measurement noise $\sigma_{\mathrm{m}}$ (Eq. 5). For a fixed a priori aerosol extinction profile relative error, Eq. (12) shows that the averaging kernel matrix $\mathbf{A}$ (and hence DoF) depends only on $\mathbf{S}_{\epsilon}$, because the $\mathbf{K}$ matrix (representing the variation of the radiance with respect to the retrieved parameter) depends on the spectral resolution, which is fixed for this test.

Figure 8a shows that the DoF increases with increasing $\Delta t$ for every value of $\mathbf{S}_{\mathrm{a}}$. While the change with integration time seems reasonable, the DoF does not seem to follow the square-root dependence on $\Delta t$ shown in Eq. (5). For a realistic value of $\mathbf{S}_{\mathrm{a}}=0.2$, between $\Delta t=5 \mathrm{~s}$ and $\Delta t=0.1 \mathrm{~s}$ (50 times smaller), the DoF differ by about $23 \%$. For a poor knowledge of the aerosol profile ( $83.7 \%$ relative error) they differ by $21 \%$ while for a good a priori knowledge $(10 \%$ relative error) the difference is about $37 \%$.

The second test (Fig. 8b) shows that resolution is the main driver in aerosol profile retrievals for high resolution measurements. The comparison with different photon noise shows the importance of a high resolution vs. integration time. The gain, in terms of content of information when a measurement at high resolution is performed, is greater than any increase due to a change in $\Delta t$. A factor-of-10 change in the integration time leads to an improvement of about $15 \%$ in the content of information, whereas the same change at high resolution $\left(0.5-0.05 \mathrm{~cm}^{-1}\right)$ can lead up to a $43 \%$ increase in the DoF. Since spectral resolution and noise are linked to each other, our results indicate that it is advantageous to use higher spectral resolution despite a lower SNR.

\section{Conclusions}

This study investigates the dependence of the information content of aerosol profile retrievals from high spectral resolution radiance measurements in the $\mathrm{O}_{2} \mathrm{~A}$-band. For this purpose, the DoF of the aerosol state vector elements has been derived for different spectral resolutions and sampling inter- vals. Four different atmospheric scenarios, covering a variety of vertical aerosol extinction profiles and albedos, were considered.

In general, our simulations show that high resolution measurements in the $\mathrm{O}_{2}$ A-band considerably improve the aerosol profile information content and thereby the retrieval of aerosol profiles.

The following conclusions can be drawn based on our results.

- The retrieval of tropospheric aerosol extinction profiles in the lowest $5 \mathrm{~km}$ of the atmosphere is considerably improved at higher spectral resolution. At the highest resolution considered here $\left(0.05 \mathrm{~cm}^{-1}\right)$, the number of pieces of information that can be retrieved varies from 3-3.5 in polluted urban cases, to around 2.7 in cleaner vegetation, marine and arctic cases.

- The high-resolution retrievals have sufficient information content in the mid-troposphere to allow the identification and quantification of the extinction of elevated aerosol layers, such as those from biomass burning. The DoF of 1.27 and 1.46 in the lower and mid-troposphere allow for distinction between aerosol at the surface and aerosol in an elevated layer.

- The retrieval sensitivity to aerosol single scattering albedo is diminished at a high spectral resolution. The total DoF varies from 4.2 for $\omega=0.8$, to 5.3 at $\omega$ values approaching 1 . This is in contrast to the behavior at low resolutions, where the difference is close to a factor of 2.

- The influence of surface albedo is considerably reduced at high spectral resolutions, as illustrated by a comparison of a vegetation, a marine and an arctic case with identical aerosol profiles. This is particularly true for the lower and mid-troposphere where retrievals at high albedo are not possible at low resolutions, while DoF above 1 in the lowest $2 \mathrm{~km}$ allow the retrieval of tropospheric aerosol extinction when the resolution is high 


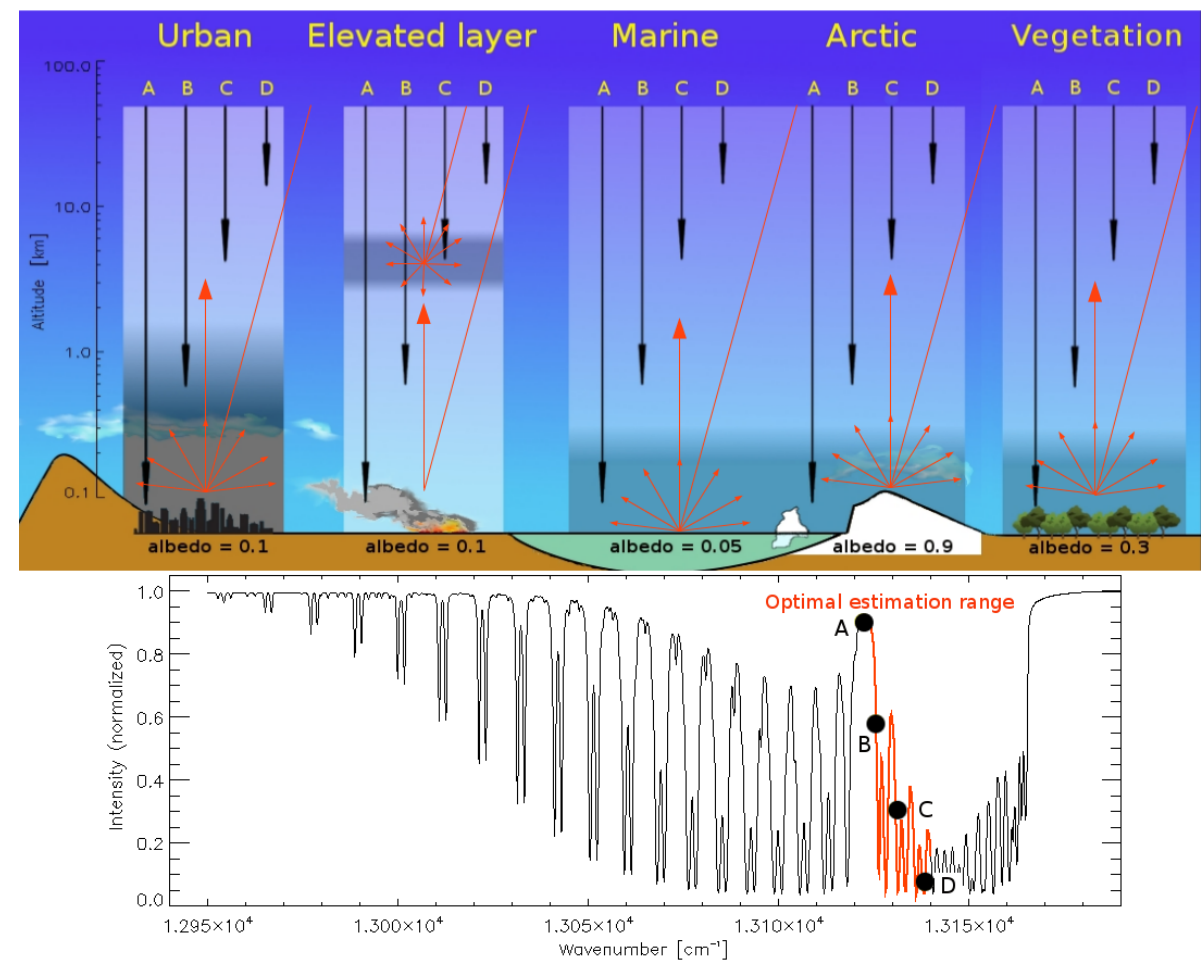

Figure 9. Example of how different instrument channels (different frequencies) probe different altitudes and thus different aerosol layers in the atmosphere. A generic channel A, sounding a spectral window of the oxygen A-band, penetrates more deeply in the atmosphere reaching the deeper levels because no absorption occurs. Moving along the shoulder of the band (channels B and C), the absorption process becomes more intense, preventing the radiation to penetrate deeper. At the bottom of the absorption band (channel D), the light is able to reach the upper part of the atmosphere only. This process is depicted in the sketch on top, where shaded gray areas represent the different aerosol profiles (arrows length is purely symbolic, not representing the actual altitude sounded at the corresponding channel). Multiple scattering of the incoming sunlight radiation (red arrows) between aerosol layers and surface at different albedo is also depicted.

enough. This is because the high-resolution retrieval is based on the spectroscopic information, i.e., the absorption band shape, rather than continuum radiances.

- Noise considerations indicate that higher-spectral resolution is advantageous for the aerosol total information content despite the lower signal-to-noise ratios. The high dynamic range of optical thickness in the $\mathrm{O}_{2}$ absorption lines seem to outweigh the noise that is introduced by the high resolution.

The results of this study clearly show how increases in spectral resolution increase the amount of information available. Our results agree with other studies investigating the amount of information available for aerosol retrieval using the $\mathrm{O}_{2}$ A-band. Investigations on retrieval information content of aerosol over sea and vegetated areas, simulating $\mathrm{O}_{2}$ A-band SCIAMACHY nadir data at low spectral resolution $\left(\mathrm{FWHM}=0.4 \mathrm{~nm}\right.$ or $\left.6.9 \mathrm{~cm}^{-1}\right)$, infer DoF of 3.2 and 2.3 respectively (Corradini and Cervino, 2006). The same study, however, points out that increasing spectral resolution leads to a better vertical resolution accuracy for the retrieval.
A value of 4.1 for the DoF is obtained when spectral resolution is increased to $0.05 \mathrm{~nm}\left(0.86 \mathrm{~cm}^{-1}\right)$.

Other studies find DoF ranging between 2 and 7, using both nadir and multi-angle simulations for the retrieval process (Frankenberg et al., 2012). These values were obtained using a combination of the $\mathrm{O}_{2}$ A-band with the weak $\mathrm{CO}_{2} / \mathrm{CH}_{4}$ absorption band at $1.61 \mu \mathrm{m}$ and the strong $\mathrm{CO}_{2}$ band at $2.06 \mu \mathrm{m}$. A spectral resolution of $0.04 \mathrm{~nm}\left(0.7 \mathrm{~cm}^{-1}\right)$, $0.075 \mathrm{~nm}\left(1.3 \mathrm{~cm}^{-1}\right)$ and $0.1 \mathrm{~nm}\left(1.73 \mathrm{~cm}^{-1}\right)$ for the $\mathrm{O}_{2} \mathrm{~A}$ band, the weak $\mathrm{CO}_{2} / \mathrm{CH}_{4}$ and the strong $\mathrm{CO}_{2}$ band, respectively, were used with 2.5 spectral samples per FWHM and a $\mathrm{SNR}=200$. These studies show that the introduction of a multi-angle and multi-wavelength approach substantially improves the aerosol retrieval. The use of a broader wavelength interval or other $\mathrm{O}_{2}$ bands would further increase the information available at high spectral resolution.

The influence of the surface albedo on the retrieval has been evaluated by other groups as well, demonstrating that, at higher spectral resolutions, the information content is less dependent on the surface albedo (Corradini and Cervino, 2006). We found similar results in our surface albedo test, showing that at higher resolutions the absorption features 
are fully resolved, thus enhancing the aerosol contribution to the retrieval and reducing the contribution from surface reflectance.

It is a well understood fact that measurements at different wavelengths in the $\mathrm{O}_{2}$ A-band are sensitive to different altitudes in the atmosphere. As a result, across the spectral window of the $\mathrm{O}_{2}$ A-band, different wavelengths will penetrate to different depths in the atmosphere (Fig. 9). The wavelengths with the smallest absorption penetrate deepest into the atmosphere. Conversely, wavelengths with greater absorption are more sensitive to the upper parts of the atmosphere. Figure 2 shows that the spectral features are significantly degraded at low resolutions: the shape, depth and shoulder slope of the absorption bands are all changed. At a low resolution, much of the information coming from the spectral absorption features is lost; as a consequence, the information coming from different altitudes are mixed, resulting in a less-resolved atmosphere. This effect also explains why the dependence of the reflected radiation from the surface on the retrieval is largest at lower resolutions. A less-resolved absorption band results in an enhancement of the signal coming from the ground because the dynamic range of absorption optical thicknesses (and hence altitudes probed) is reduced. Consequently, the total amount of retrieved aerosol information increases with increasing spectral resolution, while the dependence on surface albedo decreases at the same time.

Many studies have pointed out that aerosol retrievals are strongly affected by noise (Hollstein and Fischer, 2014; Geddes and Bösch, 2015). In a sensitivity study based on a fast forward operator, Hollstein and Fischer (Hollstein and Fischer, 2014) investigates the aerosol information content at spectral resolution values of up to $0.01 \mathrm{~nm}\left(0.17 \mathrm{~cm}^{-1}\right)$ and with a SNR ranging between 100 and 1000 . Their simulations show that aerosol optical depth retrievals benefit from an increase in the resolution (1-0.1 nm specifically); in comparison, aerosol height retrievals, could show a negative effect.

Geddes and Bösch (2015) find a similar behavior in a study simulating aerosol retrievals among four different satellitebased instruments, GOSAT (Greenhouse Gases Observing Satellite), OCO-2 (Orbiting Carbon Observatory), Sentinel 5-P and CarbonSat, with spectral resolutions of $0.03 \mathrm{~nm}$ $\left(0.52 \mathrm{~cm}^{-1}\right), 0.044 \mathrm{~nm}\left(0.76 \mathrm{~cm}^{-1}\right), 0.5 \mathrm{~nm}\left(8.65 \mathrm{~cm}^{-1}\right)$ and $0.1 \mathrm{~nm}\left(1.73 \mathrm{~cm}^{-1}\right)$, respectively. Using SNR of roughly < 200 (GOSAT), 400 (CarbonSat), 800 (OCO-2) and > 1000 (Sentinel-5 P) at $2 \times 10^{20}$ photons $\mathrm{s}^{-1} \mathrm{~m}^{-2} \mathrm{sr}^{-1} \mu \mathrm{m}^{-1}$ they obtain DoF values between 4 and 5 .

This comparison reveals that high instrument resolution does not necessarily lead to an improvement in the amount of information available, showing that the right combination of resolution and SNR is crucial for aerosol retrievals, and that a low resolution combined with a high SNR can lead to better results than a high resolution with a low SNR. However, their results also suggest that a combination of very high spectral resolution $(>0.03 \mathrm{~nm})$ coupled with high SNR levels, leads to a larger amount of aerosol information (large values of DoF).

Our study generally reproduces the impact of SNR, as shown in the noise sensitivity tests, but the overall advantage of higher spectral resolutions on the information content dominated. It seems to be advantageous to use higher spectral resolution, even if this decreases SNR. We believe that this is due to the fact that the improvements from using an increased dynamic range of absorptions at higher spectral resolution, i.e., stronger line center absorptions at higher resolution (see Fig. 2), outweigh the decreased SNR in the retrieval.

It should be noted that the pieces of information available depend on the noise model adopted and the way of sampling the high resolution spectra (in this study we have kept the ratio of FWHM and $\Delta v$ constant), which could impact the usefulness of higher resolution. However, all of the DoF determined in this study were calculated only for a portion of the $\mathrm{O}_{2}$ A-band (13 122-13 $140 \mathrm{~cm}^{-1}$ ), representing the main molecular absorption feature, and not for the entire spectral range of the $\mathrm{O}_{2} \mathrm{~A}$-band. It is thus possible, although computationally expensive, to further improve the DoF when considering a larger spectra interval. More complex aerosol profiles, coupled with multi-angle simulations to improve the content of information, will be the subject of future research. Further, polarization can provide more information on the aerosol properties, and its impact on the retrieval needs to be investigated in more detail.

Our results give guidance for new satellite-based high resolution instruments for future satellite missions, such as the Panchromatic Fourier Transform Spectrometer (PanFTS) that is currently being developed to make geostationary measurements of atmospheric composition. In general, our results seem to indicate that improvements in the ability to retrieve aerosol height profiles can be achieved by sampling the $\mathrm{O}_{2}$ A-band at high spectral resolution.

\section{The Supplement related to this article is available online at doi:10.5194/amt-9-1889-2016-supplement.}

Acknowledgements. This work was funded by NASA's Jet Propulsion Laboratory through the Strategic University Research Partnership (SURP) program.

Edited by: P. Stammes 


\section{References}

Anderson, B., Grant, W., Gregory, G., Browell, E., Collins, J., Sachse, G., Bagwell, D., Hudgins, C., Blake, D., and Blake, N.: Optical and microphysical characterization of biomass-burning and industrial-pollution aerosols from multiwavelength lidar and aircraft measurements, J. Geophys. Res., 107, 24117-24137, doi:10.1029/96JD00717, 1996.

Ansmann, A., Althausen, D., Wandinger, U., Franke, K., Muller, D., Wagner, F., and Heintzenberg, J.: Vertical profiling of the Indian aerosol plume with six-wavelength lidar during INDOEX: a first case study, Geophys. Res. Lett., 27, 963-966, doi:10.1029/1999GL010902, 2000.

Baidar, S., Oetjen, H., Coburn, S., Dix, B., Ortega, I., Sinreich, R., and Volkamer, R.: The CU Airborne MAX-DOAS instrument: vertical profiling of aerosol extinction and trace gases, Atmos. Meas. Tech., 6, 719-739, doi:10.5194/amt-6-719-2013, 2013.

Blanchet, J. and List, R.: Estimation of optical properties of arctic haze using a numerical model, Atmos. Ocean, 21, 444-465, doi:10.1080/07055900.1983.9649179, 1983.

Boesche, E., Stammes, P., Preusker, R., Bennartz, R., Knap, W., and Fischer, J.: Polarization of skylight in the $\mathrm{O}_{2}$ A-band: effects of aerosol properties, Appl. Optics, 47, 3467-3480, doi:10.1364/AO.47.003467, 2008.

Bovensmann, H., Burrows, J., Buchwitz, M., Frerick, J., Noël, S., Rozanov, V., Chance, K., and Goedec, A.: SCIAMACHY: mission objectives and measurement modes, J. Atmos. Sci., 56, 127-150, doi:10.1175/15200469(1999)056<0127:SMOAMM>2.0.CO;2, 1999.

Clémer, K., Van Roozendael, M., Fayt, C., Hendrick, F., Hermans, C., Pinardi, G., Spurr, R., Wang, P., and De Mazière, M.: Multiple wavelength retrieval of tropospheric aerosol optical properties from MAXDOAS measurements in Beijing, Atmos. Meas. Tech., 3, 863-878, doi:10.5194/amt-3-863-2010, 2010.

Corradini, S. and Cervino, M.: Aerosol extinction coefficient profile retrieval in the oxygen A-band considering multiple scattering atmosphere, test case: SCIAMACHY nadir simulated measurements, J. Quant. Spectrosc. Ra., 97, 354-380, doi:10.1016/j.jqsrt.2005.05.061, 2006.

Crisp, D., Atlas, R., Breon, F.-M., Brown, L., Burrows, J., Ciais, P., Connor, B., Doney, S., Fung, I., Jacob, D., Miller, C., O'Brien, D., Pawson, S., Randerson, J., Rayner, P., Salawitch, R., Sander, S., Sen, B., Stephens, G., Tans, P., Toon, G., Wennberg, P., Wofsy, S., Yung, Y., Kuang, Z., Chudasama, B., Sprague, G., Weiss, B., Pollock, R., Kenyon, D., and Schroll, S.: The Orbiting Carbon Observatory (OCO) mission, Adv. Space Res., 34, 700-709, doi:10.1016/j.asr.2003.08.062, 2004.

Deschamps, P., Breon, F.-M., Leroy, M., Podaire, A., Bricaud, A., Buriez, J.-C., and Seze, G.: The POLDER mission: instrument characteristics and scientific objectives, IEEE Geosci. Remote S., 32, 598-615, doi:10.1109/36.297978, 1994.

Diedenhoven, B. and Hasekamp, O. and Landgraf, J: Retrieval of cloud parameters from satellite-based reflectance measurements in the ultraviolet and the oxygen A-band, J. Geophys. Res., 112, D15208, doi:10.1029/2006JD008155, 2007.

Diner, D., Bruegge, C., Martonchik, J., Ackerman, T., Davies, R., Gerstl, S., Gordon, H., Sellers, P., Clark, J., Daniels, J., Danielson, E., Duval, V., Klaasen, K., Lilienthal, G., Nakamoto, D., Pagano, R., and Reilly, T.: MISR: a Multi-angle Imaging SpectroRadiometer for geophysical and climatological re- search from EOS, IEEE Geosci. Remote S., 27, 200-214, doi:10.1109/36.20299, 1989.

Diner, D., Hodosa, R., Davisa, A., Garayb, M., Martonchika, J., Sanghavia, S., von Allmena, P., Kokhanovskyc, A., and Zhaid, P.: An optimization approach for aerosol retrievals using simulated MISR radiances, Atmos. Res., 116, 1-14, doi:10.1016/j.atmosres.2011.05.020, 2012.

Dubovik, O., Holben, B., Eck, T., Smirnov, A., Kaufman, Y., King, M., Tanre, D., and Slutsker, I.: Variability of absorption and optical properties of key aerosol types observed in worldwide locations, J. Atmos. Sci., 59, 590-608, doi:10.1175/15200469(2002)059<0590:VOAAOP>2.0.CO;2, 2002.

Dubuisson, P., Frouin, R., Dessailly, D., Duforêt, L., Leon, J.-F., Voss, K., and Antoine, D.: Estimating the altitude of aerosol plumes over the ocean from reflectance ratio measurements in the $\mathrm{O}_{2}$ A-band, Remote Sens. Environ., 113, 1899-1911, doi:10.1016/j.rse.2009.04.018, 2009.

Duforêt, L., Frouin, R., and Dubuisson, P.: Importance and estimation of aerosol vertical structure in satellite ocean-color remote sensing, Appl. Optics, 46, 1107-1119, doi:10.1364/AO.46.001107, 2007.

Fischer, J. and Grassl, H.: Detection of cloud-top height from backscattered radiances within the oxygen A band. Part 1: Theoretical study, J. Appl. Meteorol., 30, 1245-1259, doi:10.1175/1520-0450(1991)030<1245:DOCTHF > 2.0.CO;2, 1991.

Frankenberg, C., Butz, A., and Toon, G.: Disentangling chlorophyll fluorescence from atmospheric scattering effects in $\mathrm{O}_{2} \mathrm{~A}$ band spectra of reflected sunlight, Geophys. Res. Lett., 38, L03801, doi:10.1029/2010GL045896, 2011.

Frankenberg, C., Hasekamp, O., O’Dell, C., Sanghavi, S., Butz, A., and Worden, J.: Aerosol information content analysis of multiangle high spectral resolution measurements and its benefit for high accuracy greenhouse gas retrievals, Atmos. Meas. Tech., 5, 1809-1821, doi:10.5194/amt-5-1809-2012, 2012.

Frieß, U., Sihler, H., Sander, R., Pöhler, D., Yilmaz, S., and Platt, U.: The vertical distribution of $\mathrm{BrO}$ and aerosols in the Arctic: measurements by active and passive differential optical absorption spectroscopy, J. Geophys. Res., 116, D00R04, doi:10.1029/2011JD015938, 2011.

Gabella, M., Kisselev, V., and Perona, G.: Retrieval of aerosol profile variations from reflected radiation in the oxygen absorption A band, Appl. Optics, 38, 3190-3195, doi:10.1364/AO.38.003190, 1999.

Geddes, A. and Bösch, H.: Tropospheric aerosol profile information from high-resolution oxygen A-band measurements from space, Atmos. Meas. Tech., 8, 859-874, doi:10.5194/amt-8-859-2015, 2015.

Hansen, J. and Lacis, A.: Sun and dust vs. greenhouse gases: an assessment their relative roles in global climate of change, Nature, 346, 713-719, doi:10.1038/346713a0, 1990.

Hasekamp, O. and Landgraf, J.: Retrieval of aerosol properties over land surfaces: capabilities of multiple-viewing-angle intensity and polarization measurements, Appl. Optics, 46, 3332-3344, doi:10.1364/AO.46.003332, 2007.

Heidinger, A. and Stephens, G.: Molecular line absorption in a scattering atmosphere. Part II: Application to remote sensing in the $\mathrm{O}_{2}$ A band, J. Atmos. Sci., 57, 1615-1634, doi:10.1175/15200469(2000)057<1615:MLAIAS>2.0.CO;2, 2000. 
Hollstein, A. and Fischer, J.: Retrieving aerosol height from the oxygen A band: a fast forward operator and sensitivity study concerning spectral resolution, instrumental noise, and surface inhomogeneity, Atmos. Meas. Tech., 7, 1429-1441, doi:10.5194/amt7-1429-2014, 2014.

Johnson, B., Osborne, S., Haywood, J., and Harrison, M.: Aircraft measurements of biomass burning aerosol over West Africa during DABEX, J. Geophys. Res., 113, D00C06, doi:10.1029/2007JD009451, 2008.

Kalashnikova, O. V., Garay, M. J., Martonchik, J. V., and Diner, D. J.: MISR Dark Water aerosol retrievals: operational algorithm sensitivity to particle non-sphericity, Atmos. Meas. Tech., 6, 2131-2154, doi:10.5194/amt-6-2131-2013, 2013.

Koffi, B., Schulz, M., Breon, F., Griesfeller, J., Winker, D., Balkanski, Y., Bauer, S., Berntsen, T., Chin, M., Collins, W., Dentener, F., Diehl, T., Easter, R., Ghan, S., Ginoux, P., Gong, S., Horowitz, L., Iversen, T., Kirkevag, A., Koch, D., Krol, M., Myhre, G., Stier, P., and Takemura, T.: Application of the CALIOP layer product to evaluate the vertical distribution of aerosols estimated by global models: AeroCom phase I results, J. Geophys. Res., 117, D10201, doi:10.1029/2011JD016858, 2012.

Kokhanovsky, A. and Rozanov, V.: The determination of dust cloud altitudes from a satellite using hyperspectral measurements in the gaseous absorption band, Int. J. Remote Sens., 31, 2729-2744, doi:10.1080/01431160903085644, 2010.

Leiterer, U., Nagel, D., and Stolte, R.: Typical vertical profiles of aerosol spectral extinction coefficients derived from observations of direct solar radiation extinction during the aircraft experiments Arctic Haze 94/95 and Merisec 93/94, Atmos. Res., 44, 73-88, doi:10.1016/S0169-8095(97)00010-0, 1997.

Li, J., Scinocca, J., Lazare, M., Mcfarlaine, N., von Slazen, K., and Solheim, L.: Ocean surface albedo and its impact on radiation balance in climate models, J. Climate, 19, 6314-6333, doi:10.1175/JCLI3973.1, 2006.

Martonchik, J., Kahn, R., and Diner, D.: Satellite Aerosol Remote Sensing over Land, Chapter 9, in: Retrieval of Aerosol Properties over Land using MISR Observations, edited by: Kokhanovsky, A. A. and De Leeuw, G., Springer, Berlin Heidelberg, doi:10.1007/978-3-540-69397-0_9, 267-293, 2009.

Matsui, H., M. Koike, M., Kondo, Y., Takegawa, N., Fast, J., Pöschl, U., Garland, R., Andreae, M., Wiedensohler, A., Sugimoto, N., and Zhu, T.: Spatial and temporal variations of aerosols around Beijing in summer 2006: 2. Local and column aerosol optical properties, J. Geophys. Res., 115, D222, doi:10.1029/2010JD013895, 2010.

Natraj, V., Jiang, X., Shia, R.-L., Huang, X., Margolis, J., and Yung, Y.: Application of principal component analysis to high spectral resolution radiative transfer: a case study of the $\mathrm{O}_{2}$ A-band, J. Quant. Spectrosc. Ra., 95, 539-556, doi:10.1016/j.jqsrt.2004.12.024, 2005.

Natraj, V., Spurr, R., Boesch, H., Jiang, Y., and Yung, Y.: Evaluation of errors from neglecting polarization in the forward modeling of $\mathrm{O}_{2}$ A band measurements from space, with relevance to $\mathrm{CO}_{2}$ column retrieval from polarization sensitive instruments, J. Quant. Spectrosc. Ra., 103, 245-259, doi:10.1016/j.jqsrt.2006.02.073, 2007.

NOAA: US Standard Atmosphere, US Government Printing Office, Washington, DC, 1976.
Pelon, J., Mallet, M., Marisca, A., Goloub, P., Tanre, D., Bou Karam, D., Flamant, C., Haywood, J., Pospichal, B., and Victori, S.: Microlidar observations of biomass burning aerosol over Djougou (Benin) during African Monsoon Multidisciplinary Analysis Special Observation Period 0: Dust and Biomass-Burning Experiment, J. Geophys. Res., 113, D00C18, doi:10.1029/2008JD009976, 2008.

Quinn, P., Coffman, D., Bates, T., Miller, T., Johnson, J., Welton, E., Neususs, C., Miller, M., and Sheridan, P.: Aerosol optical properties during INDOEX 1999: means, variability, and controlling factors, J. Geophys. Res., 107, D198020, doi:10.1029/2000JD000037, 2002.

Rast, M., Bezy, J., and Bruzzi, S.: The ESA Medium Resolution Imaging Spectrometer MERIS: a review of the instrument and its mission, Int. J. Remote Sens., 20, 1681-1702, doi:10.1080/014311699212416, 1999.

Rodgers, C.: Inverse method for atmospheric soundings - Theory and Practice, 13-79, World Scientific, Singapore, 2000.

Rothman, L., Gordon, I., Barbe, A., Benner, D., Bernath, P., Birk, M., Boudon, V., Brown, L., Campargue, A., Champion, J.-P., Chance, K., Coudert, L., Dana, V., Devi, V., Fally, S., Flaud, J.-M., Gamache, R., Goldman, A., Jacquemart, D., Kleiner, I., Lacome, N., Lafferty, W., Mandin, J.-Y., Massie, S., Mikhailenko, S., Miller, C., Moazzen-Ahmadi, N., Naumenko, O., Nikitin, A., Orphal, J., Perevalov, V., Perrin, A., Predoi-Cross, A., Rinsland, C., Rotger, M., Simeckova, M., Smith, M., Sung, K., Tashkun, S., Tennyson, J., Toth, R., Vandaele, A., and Auwera, J. V.: The HITRAN 2008 molecular spectroscopic database, J. Quant. Spectrosc. Ra., 110, 533-572, doi:10.1016/j.jqsrt.2009.02.013, 2009.

Rozanov, V. and Kokhanovsky, A.: Semianalytical cloud retrieval algorithm as applied to the cloud top altitude and the cloud geometrical thickness determination from top-of-atmosphere reflectance measurements in the oxygen A band, J. Geophys. Res., 109, D05202, doi:10.1029/2003JD004104, 2004.

Samset, B. H., Myhre, G., Schulz, M., Balkanski, Y., Bauer, S., Berntsen, T. K., Bian, H., Bellouin, N., Diehl, T., Easter, R. C., Ghan, S. J., Iversen, T., Kinne, S., Kirkevåg, A., Lamarque, J.-F., Lin, G., Liu, X., Penner, J. E., Seland, Ø., Skeie, R. B., Stier, P., Takemura, T., Tsigaridis, K., and Zhang, K.: Black carbon vertical profiles strongly affect its radiative forcing uncertainty, Atmos. Chem. Phys., 13, 2423-2434, doi:10.5194/acp-13-24232013, 2013.

Sanders, A. F. J. and de Haan, J. F.: Retrieval of aerosol parameters from the oxygen A band in the presence of chlorophyll fluorescence, Atmos. Meas. Tech., 6, 2725-2740, doi:10.5194/amt-62725-2013, 2013.

Sanders, A. F. J., de Haan, J. F., Sneep, M., Apituley, A., Stammes, P., Vieitez, M. O., Tilstra, L. G., Tuinder, O. N. E., Koning, C. E., and Veefkind, J. P.: Evaluation of the operational Aerosol Layer Height retrieval algorithm for Sentinel-5 Precursor: application to $\mathrm{O}_{2}$ A band observations from GOME-2A, Atmos. Meas. Tech. Discuss., 8, 6045-6118, doi:10.5194/amtd-86045-2015, 2015.

Sanghavi, S., Martonchik, J. V., Landgraf, J., and Platt, U.: Retrieval of the optical depth and vertical distribution of particulate scatterers in the atmosphere using $\mathrm{O}_{2}$ A- and B-band SCIAMACHY observations over Kanpur: a case study, Atmos. Meas. Tech., 5, 1099-1119, doi:10.5194/amt-5-1099-2012, 2012. 
Sayer, A. M., Smirnov, A., Hsu, N. C., Munchak, L. A., and Holben, B. N.: Estimating marine aerosol particle volume and number from Maritime Aerosol Network data, Atmos. Chem. Phys., 12, 8889-8909, doi:10.5194/acp-12-8889-2012, 2012.

Schafer, J., Eck, T., Holben, B., Thornhill, K., Anderson, B., Sinyuk, A., Giles, D., Winstead, E., Ziemba, L., Beyersdorf, A., Kenny, P., Smirnov, A., and Slutsker, I.: Intercomparison of aerosol single-scattering albedo derived from AERONET surface radiometers and LARGE in situ aircraft profiles during the 2011 DRAGON-MD and DISCOVER-AQ experiments, J. Geophys. Res., 119, 7439-7452, doi:10.1002/2013JD021166, 2014.

Shaw, G.: The Arctic Haze Phenomenon, Bullettin of the American Meteorological Society, 76, 2403-2413, doi:10.1175/15200477(1995)076<2403:TAHP>2.0.CO;2, 1995.

Spurr, R.: VLIDORT: a linearized pseudo-spherical vector discrete ordinate radiative transfer code for forward model and retrieval studies in multilayer multiple scattering media, J. Quant. Spectrosc. Ra., 102, 316-342, doi:10.1016/j.jqsrt.2006.05.005, 2006.

Tesche, M., Zieger, P., Rastak, N., Charlson, R. J., Glantz, P., Tunved, P., and Hansson, H.-C.: Reconciling aerosol light extinction measurements from spaceborne lidar observations and in situ measurements in the Arctic, Atmos. Chem. Phys., 14, 78697882, doi:10.5194/acp-14-7869-2014, 2014.

Vuolo, M. R., Schulz, M., Balkanski, Y., and Takemura, T.: A new method for evaluating the impact of vertical distribution on aerosol radiative forcing in general circulation models, Atmos. Chem. Phys., 14, 877-897, doi:10.5194/acp-14-877-2014, 2014.

Wagner, T., Beirle, S., Brauers, T., Deutschmann, T., Frieß, U., Hak, C., Halla, J. D., Heue, K. P., Junkermann, W., Li, X., Platt, U., and Pundt-Gruber, I.: Inversion of tropospheric profiles of aerosol extinction and $\mathrm{HCHO}$ and $\mathrm{NO}_{2}$ mixing ratios from MAX-DOAS observations in Milano during the summer of 2003 and comparison with independent data sets, Atmos. Meas. Tech., 4, 2685-2715, doi:10.5194/amt-4-2685-2011, 2011.
Wandinger, U., Müller, D., Bockmann, C., Althausen, D., Bosenberg, J., Weiss, V., Fiebig, M., Matthias, V., Wendisch, M., Stohl, A., and Ansmann, A.: Optical and microphysical characterization of biomass-burning and industrial-pollution aerosols from multiwavelength lidar and aircraft measurements, J. Geophys. Res., 107, 8125, doi:10.1029/2000JD000202, 2002.

Xia, X., Chen, H., Wang, P., Zhang, W., Goloub, P., Chatenet, B., Eck, T., and Holben, B.: Variation of column-integrated aerosol properties in a Chinese urban region, J. Geophys. Res., 111, D05204, doi:10.1029/2005JD006203, 2006.

Yamanouchi, T., Treffeisen, R., Herber, A., Shiobara, M., Yamagata, S., Hara, K., Sato, K., Yabuki, M., Tomikawa, Y., Rinke, A., Neuber, R., Schumachter, R., Kriews, M., Ström, J., Schrems, O., and Gernandt, H.: Arctic Study of Tropospheric Aerosol and Radiation (ASTAR) 2000: Arctic haze case study, Tellus, 57, 141152, doi:10.1111/j.1600-0889.2005.00140.x, 2005.

Yu, H., Chin, M., Winker, D. M., Omar, A., Liu, Z., Kittaka, C., and Diehl, T.: Global view of aerosol vertical distributions from CALIPSO lidar measurements and GOCART simulations: regional and seasonal variations, J. Geophys. Res., 115, D00H30, doi:10.1029/2009JD013364, 2010.

Zarzycki, C. and Bond, T.: How much can the vertical distribution of black carbon affect its global direct radiative forcing?, Geophys. Res. Lett., 37, L20807, doi:10.1029/2010GL044555, 2010.

Zhengjia, L., Shao, Q., TAO, J., and Chi, W.: Intra-annual variability of satellite observed surface albedo associated with typical land cover types in China, J. Geogr. Sci., 25, 35-44, doi:10.1007/s11442-015-1151-5, 2015. 